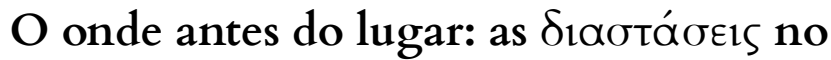 De incessu animalium de Aristóteles
}

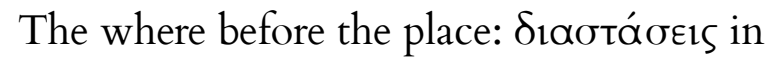

Aristotle's De incessu animalium

\author{
Matheus Oliveira Damião ${ }^{1}$ \\ e-mail: matheus.damiaoliveira@gmail.com \\ orcid: http://orcid.org/0000-0002-3419-8823
}

\section{DOI: http://dx.doi.org/10.25187/codex.v5i2.14328}

\section{Resumo:}

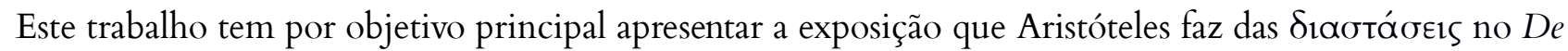
Incessu Animalium (IA). Nesse tratado, elas são descritas através do exercício das funções anímicas específicas de cada grupo de ser vivo, estabelecendo uma relação de dependência entre as dimensões e as potências da alma que determinado ser vivo possui. Trata-se, portanto, em âmbitos mais gerais, de compreender como a função da alma de um ser vivo subordina sua estrutura, ou, em outras palavras, como a atualização efetiva de um ser vivo traz à tona a manifestação dessas dimensões. Além disso, há uma correspondência exata entre as dimensões e essas funções no corpo humano, estabelecendo-o, assim, como modelo a partir do qual os outros corpos podem ser descritos. Desse modo, os limites das dimensões são manifestos através das potências da alma, cujas distinções se encontram sobretudo no homem.

Palavras-chave: função; teleologia; dimensões; biologia

\section{Abstract:}

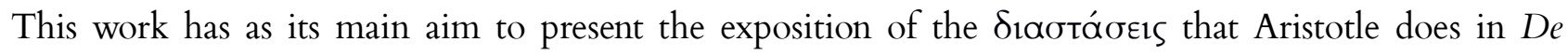
Incessu Animalium (IA). At this treatise, they are described through the exercise of the soul's functions of each group of a living being, establishing a dependent relation between the dimensions and the powers of the soul held by a given living being. Therefore, it is about understanding, in a general view, how the function of soul of a living being subordinates its structure, or, in other words, how the effective actualization of a living being brings about the manifestation of these dimensions. Moreover, there is an exact correspondence between the dimensions and these functions in the human body, setting it, thus, as a model from which the other bodies may be described. In this manner, the limits of the dimensions are manifested through the functions of the soul whose distinctions are found, above all others, in man.

Keywords: function; teleology; dimensions; biology

\footnotetext{
${ }^{1}$ Licenciado em Letras-Grego pela Universidade Federal do Rio de Janeiro (Brasil); discente do Curso de Mestrado do Programa de Pós-Graduação em Filosofia da Universidade Federal do Rio de Janeiro (Brasil). Membro discente do Programa de Estudos em Representações da Antiguidade (PROAERA).
} 


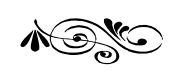

\section{Introdução}

A primeira questão da qual este artigo se ocupa é a que se refere ao lugar das

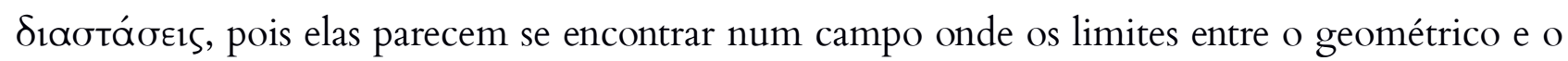
biológico se entrelaçam. A delimitação do espaço delas requer, por conseguinte, também uma distinção entre o objeto matemático e o objeto da física. Inseridas no último grupo, passaremos, em seguida, ao exame do papel de uma teleologia que tem por escopo ou consequência orientar

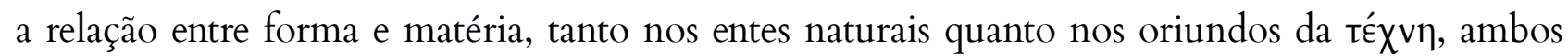
objetos da física. Com o campo teleológico explica-se também a funcionalidade das Sıaotáoєıৎ, norteadora de sua descrição no De Incessu Animalium, principal corpus deste

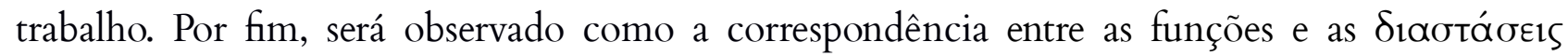
parece ter o homem como parâmetro, mormente no que concerne às funções que lhe são inerentes e, por isso, talvez mais facilmente reconhecíveis.

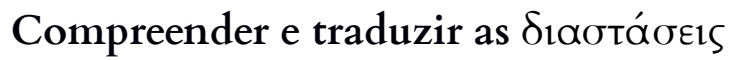

Antes de discutir a exposição que Aristóteles faz das Staotáoøıs no De Incessu Animalium (IA), fazem-se necessários alguns comentários acerca das possibilidades de sua

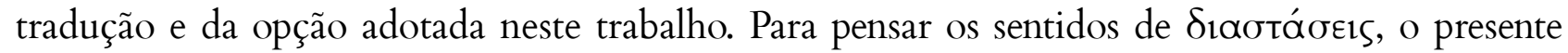
trabalho toma como ponto de partida a distinção feita por Lennox (2009), em célebre artigo acerca da relação entre o $I A$ e o De caelo II 2.

De acordo com o autor, o primeiro sentido seria o encontrado em De caelo I 1, que, segundo Lennox, corresponde precisamente ao termo dimensão ${ }^{2}$ em inglês, referindo-se às dimensões de largura, comprimento e profundidade.

Já o segundo sentido se encontraria, segundo Lennox (2009), ao longo de todo o $I A$, e está ligado, como será visto mais à frente, às três potências mais básicas da alma, a saber, a nutrição, a percepção e o deslocamento. O caráter de movimento das potências aparece, em sua tradução, unido à dimensionalidade, ao traduzi-las por dimensões direcionais ${ }^{3}$. De fato, como o

\footnotetext{
2 dimension, no original (LENNOX, 2009, p. 188).

3 directional dimensions, no original (LENNOX, 2009).
} 
próprio autor não deixa de assinalar ${ }^{4}$, os dois sentidos estão intimamente ligados e, em alguns textos, o próprio discernimento de qual sentido a que Aristóteles faz referência é de difícil apreensão ${ }^{5}$. Para o que se pretende por ora, a explicação de Lennox é suficiente acerca das

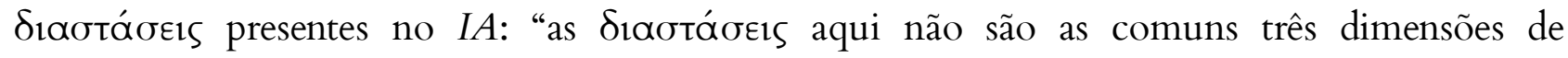
magnitude do corpo que se encontram em De caelo 1.1, mas elas são, na verdade, três pares de direções"6.

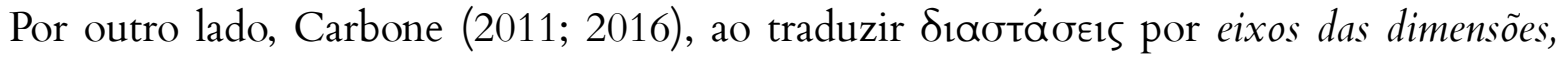

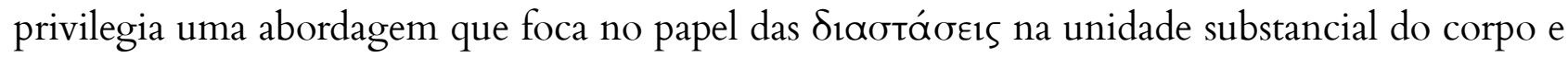
alma, tendo o corpus zoológico de Aristóteles como principal suporte para sua interpretação ${ }^{7}$.

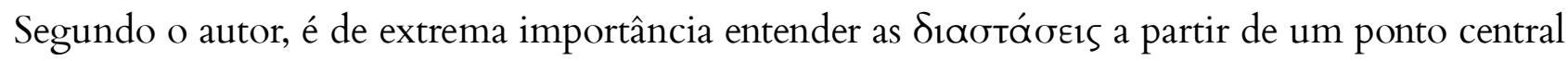
de intersecção a elas, pois, para Aristóteles, este meio é um ponto central essencial ao apoio das potências da alma e que parece corresponder ao coração ${ }^{8}$. Trata-se, portanto, de uma unidade que une um aspecto fisiológico - o coração, a boca, os olhos, por exemplo - às potências da alma ${ }^{9}$. Entretanto, ao focar na unidade do ser vivo, Carbone deixa um pouco de lado ${ }^{10}$ em sua interpretação o sentido das Sıaotáoeıৎ como encontrado em De caelo I 1, que corresponde, como visto acima, ao primeiro sentido enunciado em Lennox (2009).

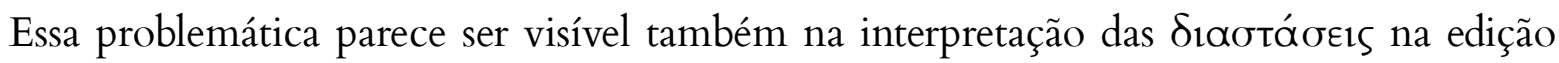
de Morel (2013). Em sua tradução do $I A$, o autor oscila de tradução em dois momentos: no capítulo 2, traduz como dimensions, e no capítulo 4, como directions.

${ }^{4}$ Lennox, 2009, p. 191: "There is no doubt, then, that Aristotle refers to both the three dimensions of bodily

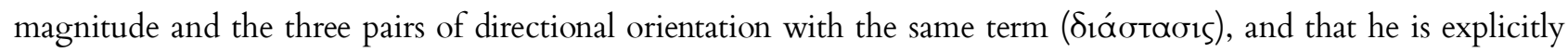
connecting them in De caelo II 2: above is the principle of length, right of breadth, and front of depth. This allows him, then, to give priority to one of the two contraries of directional orientation".

5 Como é o caso de De caelo II 2.

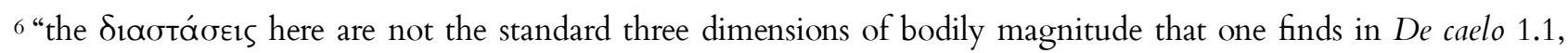
but they are rather three pairs of directions" (LENNOX, 2009, p. 188).

${ }^{7}$ A referência aqui é ao estudo de Carbone (2011) acerca das representações e esquematizações presentes na biologia de Aristóteles.

8 c.f CARBONE, 2011, p. 186. Para não se desviar dos objetivos principais deste trabalho, optou-se por não aprofundar essa questão.

${ }_{9}$ CARBONE, 2011, p. 203.

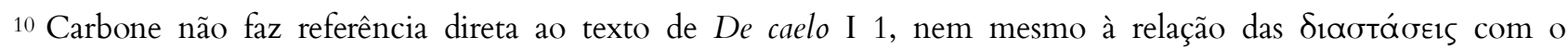

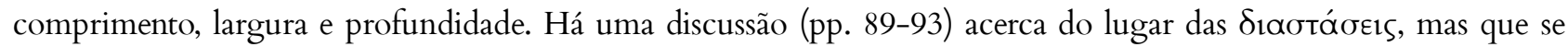
resume apenas a salvaguardá-las do "salto de gênero", isto é, retirá-las do âmbito matemático. Além disso, é

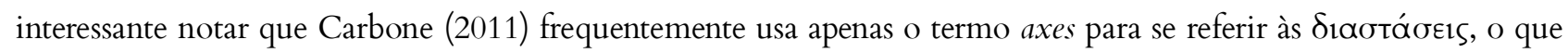
parece mostrar o privilégio de sua interpretação pautada no centro e na unidade do ser vivo. 
Assim, como Lennox (2009) aponta dois possíveis sentidos diferentes para o mesmo termo e, além disso, Carbone $(2011 ; 2016)$ ainda insere as noções de apoio central na sua interpretação - ausente na de Lennox -, optar-se-á por não traduzir o termo, mantendo-o em grego. Como conceito problematizado do presente artigo, vê-se a necessidade de primeiramente investigar suas características, sentidos e contextos, para só então, em momento posterior da pesquisa, optar-se por uma tradução.

\section{As premissas do De incessu animalium}

Após expor no primeiro capítulo do De Incessu Animalium (IA) as questões que nortearão sua investigação - cujo caráter é preponderantemente etiológico -, Aristóteles inicia o

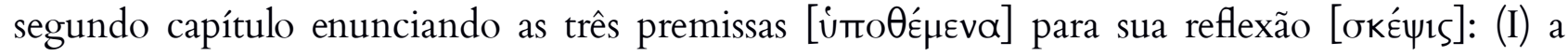

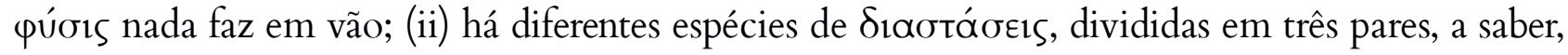
o alto e o baixo, a frente e a traseira, a direita e a esquerda; e (iii) os princípios [ápxái] dos

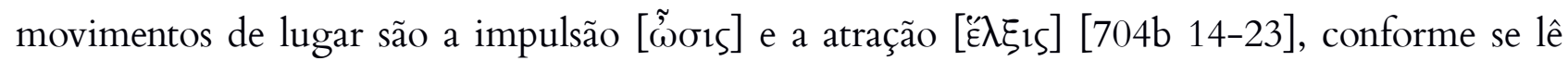
neste excerto:

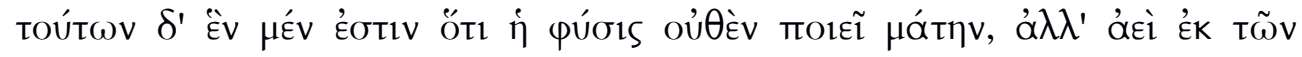

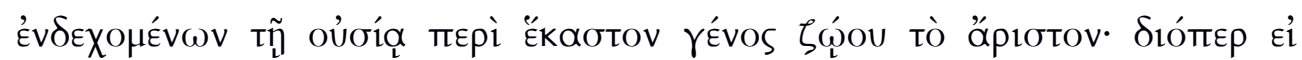

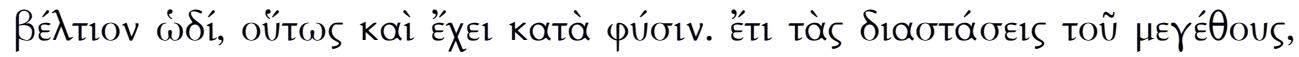

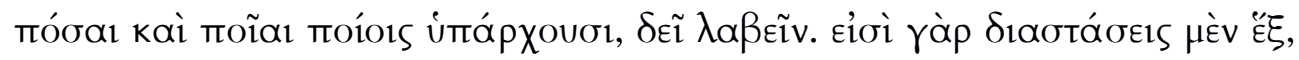

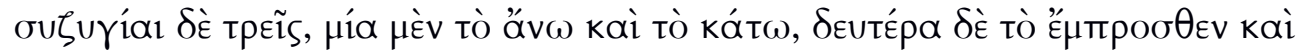

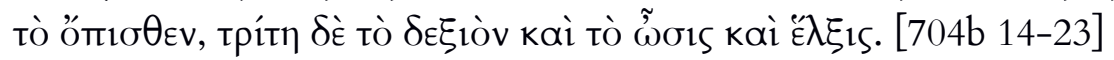

Destes um é que a natureza nada faz em vão, mas sempre o melhor a partir do plausível em relação à essência em cada gênero de ser vivo; assim, portanto, se o que se segue é melhor, este é segundo a natureza. É preciso ainda tomar por certo as dimensões de grandeza, quantas e quais pertencem a quais coisas. Há seis

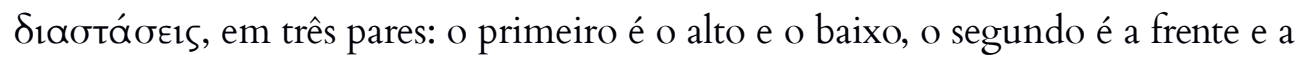
traseira, e o terceiro é a direita e a esquerda. Além disso, que os princípios dos movimentos de local são a impulsão e a atração ${ }^{11}$.

De modo geral, como assinala Carbone (2011, p. 89), as duas primeiras premissas dizem respeito ao trabalho da natureza e à própria estrutura geral dos seres vivos, enquanto a última se aplica ao objeto específico do tratado, que é a marcha dos animais. Entretanto, enquanto a

\footnotetext{
11 Todos as traduções do De incessu animalium presentes neste artigo são do seu autor.
} 
primeira12 e a terceira premissa13 parecem ter maior relação direta com os fenômenos da natureza, já que ambas se referem a um processo natural - uma em relação ao modo como a natureza age e a outra em relação a como o deslocamento espacial é realizado na natureza -, as

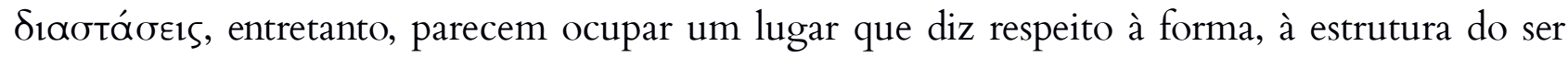
vivo.

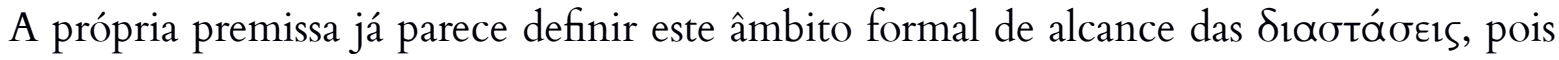

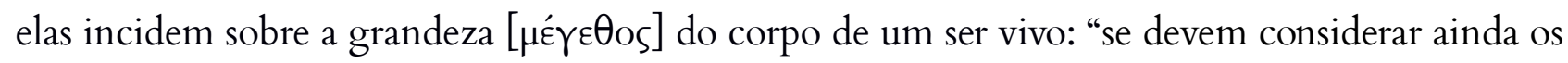
eixos direcionais da grandeza, suas quantidades, suas qualidades e com que tipo de [coisas] têm

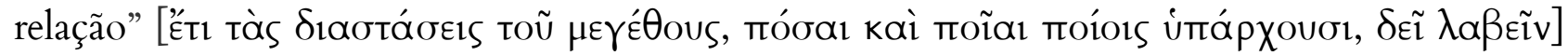
(704b 16).

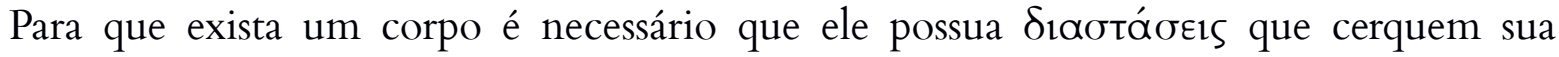
matéria - matéria [ư $\lambda \eta]$ e grandeza [ $\mu \varepsilon^{\varepsilon} \gamma \varepsilon \theta$ os] estão no mesmo nível de indeterminação em Física IV 2 (209b 2 s) - e que o possibilitem ser, de fato, um corpo. Segundo Metafísica M 2 (1077a 28s), possuir as três dimensões é uma condição necessária para se ter alma, isto é, para ser um ser vivo (De Anima I 402 a 7)14. É o que Aristóteles diz a respeito delas em De caelo II 284b 23: "É razoável supor que todos os corpos completos possuem estas distinções dimensionais [...]".

Aristóteles, de fato, parece sugerir, em Física III 5, 204 b 7 - 206a, que não há corpo sem limites corporais estabelecidos, pois, ao refutar a possibilidade de um corpo infinito, afirma que

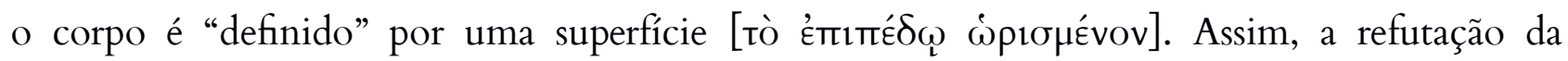
existência de um corpo infinito é obtida através do que caracteriza um corpo. Explica o tradutor da passagem: "se se entende por corpo uma magnitude tridimensional e se por definição toda magnitude é mensurável, então não pode ser infinito"15.

Acerca dessa nuance de significado, Carbone (2011) nos lembra que, apesar de as

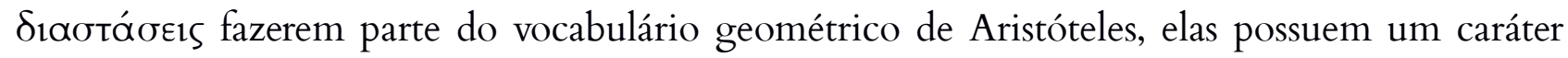
físico inerente à função que exercem num corpo, que é a de delimitação.

\footnotetext{
12 Sobre esta primeira premissa que tem grande recorrência nos textos aristotélicos, Lennox (2001) faz um estudo pormenorizado acerca de sua ocorrência e de outra forma correlata.

13 Além de se tratar dos dois tipos de movimentos usados pelos animais no de De incessu animalium, tal como aponta Saint-Hilaire (1885) em seu comentário ao trecho, esta premissa traz também a questão da necessidade do ponto de apoio no movimento, discussão exaustivamente trabalhada por Aristóteles em pormenores no De Motu Animalium.

${ }^{14}$ Entretanto, como veremos linhas abaixo, segundo o $I A$, nem todos os seres vivos possuem as três dimensões.

15 "se entiende por cuerpo una magnitud tridimensional y si por definición toda magnitud es mensurable, entonces no puede ser infinito" (p. 94).
} 
Tratar-se-ia, então, de conceitos da geometria, mas que no $I A$ são utilizados no estudo dos seres vivos? Isto é, trata-se de uma mudança de cenário: da incorruptibilidade dos objetos matemáticos para a corruptibilidade teleológica do mundo sublunar? Essa passagem acarretaria algumas dificuldades ${ }^{16}$ que devem ser colocadas para se entender o alcance e a aplicabilidade das Sıaotáoeıs no corpus aristotelicum. É preciso, assim, estabelecer o lugar ocupado por elas ao serem usadas como princípios dos seres vivos.

\section{Em torno do conceito de $\delta i a ́ \sigma t a \sigma r \varsigma$}

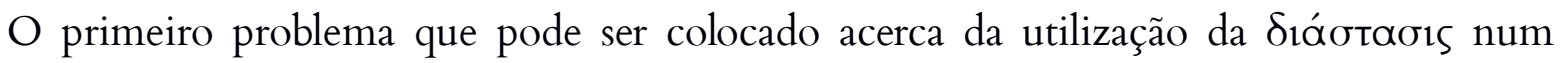
contexto não-matemático, como o $I A$, é se com a aplicação de premissas de outra ciência Aristóteles estaria ou não violando a proibição da metábasis, postulada em diversas passagens de Segundos Analíticos I $^{17}$. Segundo esse princípio, cada ciência deve proceder a partir de princípios que lhe são próprios, isto é, "não se pode provar uma proposição geométrica pela aritmética"18. Carbone (2011, p. 90) também se refere a esse possível problema e sustenta que, devido à independência entre o objeto matemático e o ser vivo, a aplicação do princípio de uma a outro iria contra um dos princípios mais importantes da teoria aristotélica da ciência, que é a "proibição do salto de gênero"19.

Já que a geometria pertence ao domínio das matemáticas, uma interpretação em termos de geometrização do corpo vivo colocaria um problema em relação ao sistema aristotélico das ciências, em que as matemáticas e a pesquisa sobre a natureza se distinguem do ponto de vista dos princípios e do método ${ }^{20}$.

Martha Nussbaum, na introdução da sua edição do De motu animalium²1, lidou com a mesma questão e apontou como melhor solução o fato de que há um caráter de

\footnotetext{
${ }^{16}$ Uma delas é que, apesar de serem conceitos matemáticos, Aristóteles em De caelo II 2 afirma que elas são próprias aos seres vivos - como será tratado abaixo - e menciona um tratado sobre o movimento dos animais como referência. Trata-se, certamente, do $I A$. Lennox (2009) discute em pormenores essa relação com o $I A$.

17 Seg. an. I 7; 23, 84b 14-18; 28; 32, 88a 31-36.

18 “On ne peut pas prouver une proposition géométrique par l'arithmétique” (MOREL, 2013, p. 24).

19 “l'interdiction du 'saut de genre" (CARBONE, 2011, p. 90).

${ }_{20}$ Carbone (2011, p. 90): "Puisque la géométrie appartient au domaine des mathématiques, une interprétation en termes de géométrisation du corps vivant poserait problème par rapport au système aristotélicien des sciences, où les mathématiques et la recherche sur la nature sont distinguées du point de vue des principes et de lá méthode".
}

${ }^{21}$ NUSSBAUM, Martha C. Aristotle's De Motu Animalium, 1985. 
interdependência entre elas, tornando possível uma autocrítica de Aristóteles às concepções anteriores em relação à cosmologia e à própria matemática. Nussbaum conclui:

No curso deste tratado, Aristóteles está apto a criticar algumas de suas conclusões prévias sobre outros problemas cosmológicos; a biologia fornece um corretivo útil para algumas abstrações matemáticas desorientadoras no DC. Embora seja breve e cifrado, o $M A$ faz uma valorosa contribuição para o nosso conhecimento das visões maduras de Aristóteles em relação à articulação do universo e das ciências do homem²2.

A justificativa de Nussbaum para o De Motu se fundamenta, em última instância, numa espécie de revisionismo que coloca os princípios dos Analíticos como "ultrapassados” pelos últimos textos de Aristóteles.

Entretanto, não é preciso recorrer a segmentações internas do corpus para atestar a coerência da metábasis com os procedimentos recorrentes nos tratados zoológicos de Aristóteles. Como bem demonstrou o professor Lucas Angioni, em sua conferência intitulada "Explaining animal movement through geometry? Incessu Animalium 9 and 12”, proferida no Simpósio OUSIA ${ }^{23}$, a utilização de premissas geométricas, e, por conseguinte, conclui-se que também as

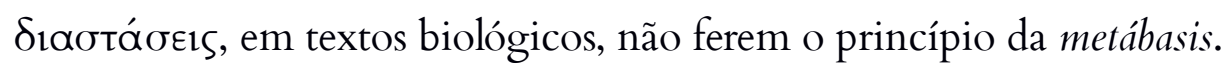

Angioni afirma que a metábasis diz respeito à transferência de determinadas premissas a outra ciência a fim de conceder uma explicação completamente apropriada a um problema de outra ordem. Esse não seria o caso no $I A$, pois estas premissas geométricas não fundamentam as explicações per se, isto é, não possuem caráter explicativo suficiente para os fenômenos a que se referem. Como nos lembra Angioni, no $I A$ as premissas geométricas são subordinadas ao ser vivo e à sua estrutura organizacional e é essa união que possibilita em última instância

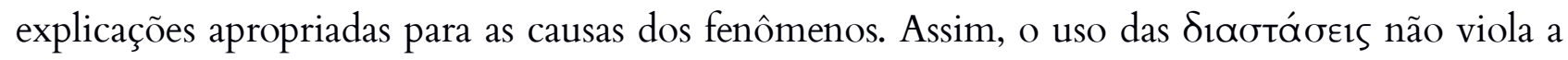
"proibição" da metábasis, pois serve como premissa complementar nas explicações do $I A$. O princípio que tem papel mais importante nas explicações causais, referido por Aristóteles ao longo de todo o texto, é o teleológico. Enunciada claramente na primeira premissa no $I A$, a

\footnotetext{
22 Nussbaum (1985, p. 144): "In the course of the treatise, Aristotle is able to criticize some of his previous conclusions about other cosmological problems; biology provides a useful corrective to some misleading mathematical abstractions in the $D C$. Brief and cryptic though it is, the $M A$ makes a valuable contribution to our knowledge of Aristotle's mature views concerning the articulation of the universe and of man's sciences".

23 "Aristóteles e o movimento" - Simpósio OUSIA de Estudos Clássicos (Universidade Federal do Rio de JaneiroIFCS, 2017).
} 
teleologia é o fundamento sobre o qual todas as demais premissas agem e que permite Aristóteles

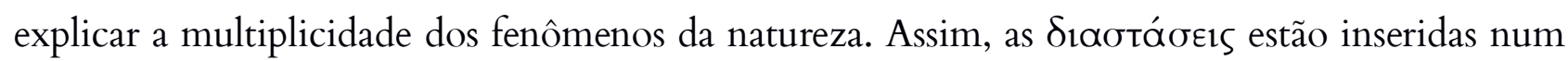
contexto em que a teleologia participa das explicações dos fenômenos e, portanto, não só não comprometem o princípio dos Analíticos como também apresentam o lugar em que estão inseridas.

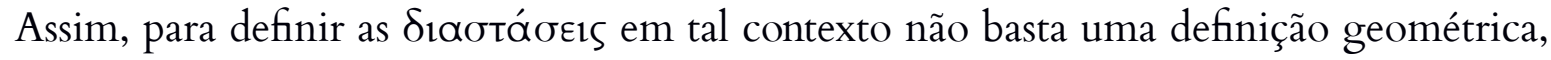
já que esta, para alguns autores ${ }^{24}$, colocaria um possível problema acerca do "salto de gênero", mas também, em tal definição, tanto os entes da técnica quanto os seres vivos seriam vistos sob o mesmo aspecto, ignorando a particularidade do corpo natural. É preciso, então, que se

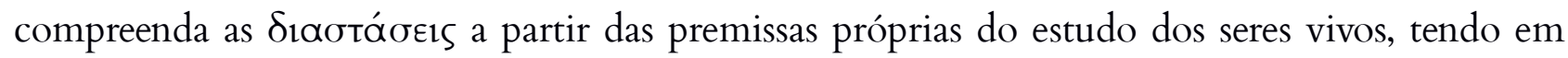
vista o objeto próprio a que são aplicadas, isto é, o ser vivo.

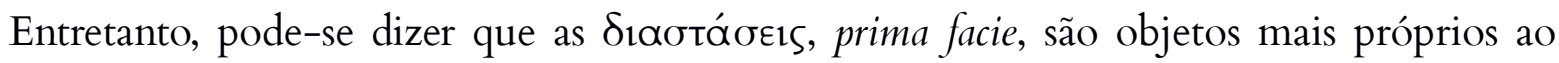
geômetra, e é justamente por isso que se pode questionar o estatuto epistemológico desse conceito no estudo dos seres vivos. O objeto do geômetra, entretanto, não é ontologicamente separável dos objetos físicos, como uma leitura platônica poderia nos levar a admitir e como parece estar pressuposto na argumentação do "salto de gênero" nesse contexto, já que pressupõe, nesse discurso, uma independência ontológica entre os objetos das diferentes ciências ${ }^{25}$. Além disso, o objeto que é próprio ao físico, como descrito sobretudo em Física II 2 e Metafísica M 3 , não se encontra isento de propriedades matemáticas, mas, ao contrário, também as possui, como fica claro em Física II 2 193b 23-5: "pois também os corpos naturais têm superfícies e sólidos, bem como comprimentos e pontos, a respeito dos quais o matemático faz seu estudo".

Segundo Aristóteles, o objeto do matemático se diferencia do objeto do físico [ou investigador da natureza ou algo que o valha] somente na medida em que o considera de

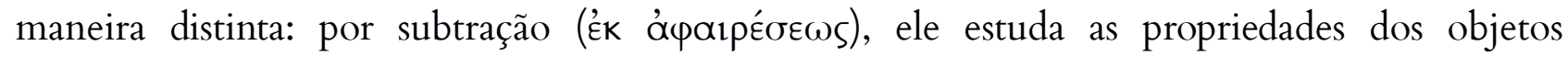
separadamente do movimento a que estão sujeitos. Como continua o texto de Física II 2,

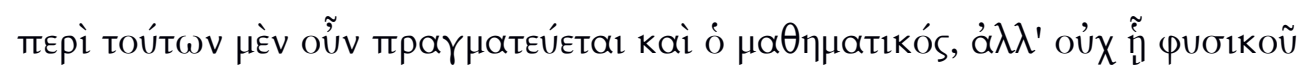

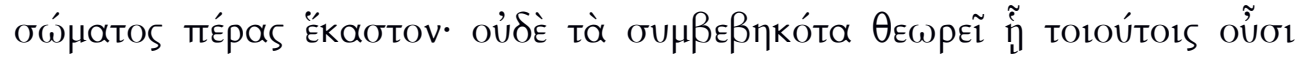

\footnotetext{
24 Carbone (2011); Morel (2013); Nussbaum (1985).

${ }_{25}$ Carbone (2011, p. 90), nessa mesma passagem, fala que "os objetos matemáticos e os vivos são diferentes sobre o plano ontológico", e que são "dois gêneros distintos de realidades”. Apesar de não estar completamente explicada aqui qual a diferença ontológica dos dois objetos, e apesar do autor em seguida fazer referência ao procedimento de abstração da matemática, Carbone não parece se atentar aqui ao fato de que, para Aristóteles, é a partir dos objetos físicos que os objetos matemáticos surgem. Como explica Jonathan Lear (1982: 182), "we can even perform mental constructions and form a figure that we have perhaps never perceived. But even in this case we are doing no more than constructing a figure in thought from elements that are direct abstraction from the physical world".
} 


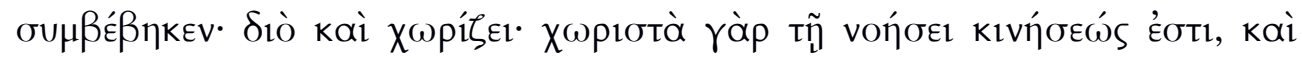

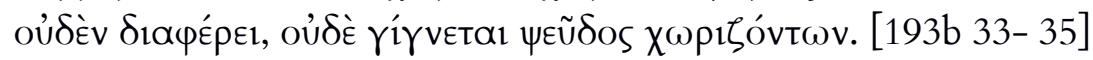

Ora, também o matemático se ocupa desses itens, mas não enquanto cada um é limite de corpo natural; tampouco estuda os atributos enquanto sucedem aos corpos naturais tomados nessa qualidade; por isso, o matemático os separa: pelo pensamento, tais itens são separáveis do movimento, e isso não faz nenhuma diferença, tampouco surge falso quando eles os separam.

O matemático estuda, portanto, atributos que também os entes naturais possuem, mas os toma não enquanto [ĩ̃] propriedades naturais, não enquanto propriedades de objetos que estão suscetíveis às mudanças dos seres naturais, mas enquanto atributos separados da natureza de seus objetos. Essa separação não resulta em falsidade, como explica Aristóteles, pois o geômetra estuda as noções implicadas nas relações que estão presentes em todos os corpos, e, por isso, seu estudo trata de uma abstração não condicionada à corruptibilidade dos corpos sensíveis, apesar de os pressupor ontologicamente.

Por outro lado, o físico também estuda as propriedades geométricas, como o círculo e as retas, não as separando do movimento próprio às substâncias sensíveis, mas as vendo juntamente com as características que compõem o ser vivo, em seus aspectos teleológicos, materiais e formais.

Segundo Jonathan Lear (1982), trata-se de uma diferença metodológica fundada no que o autor chama de qua-operator ou as-operator ${ }^{26}$, que estabelece uma espécie de filtragem a partir da qual permite Aristóteles distinguir as propriedades essenciais e acidentais de um determinado campo, seja matemático, físico etc. Entender o corpo de um ser vivo, por exemplo, enquanto objeto geométrico, é filtrar (“filter out") "todos os predicados que concernem à composição material do objeto" (LEAR, 1982, p. 170). Assim, pode-se concluir com Angioni (2013), em comentário a essa passagem, que “a matemática obtém seu objeto próprio por tomar isoladamente, em si mesmas, quantidades que existem naturalmente em corpos dotados de uma suscetibilidade intrínseca para a mudança” (ANGIONI, 2013, p. 227).

\footnotetext{
${ }^{26}$ Lear (1982) desenvolve uma longo estudo acerca da função de filtragem do "qua-operator" na separabilidade das propriedades geométricas dos objetos físicos. Em um trecho importante o autor explica: "If we are considering $b$ as being an $F$ [um ente matemático, por exemplo], then every predicate that is not essential to its being $F$ is considered incidental, even though it may be essential to $b$ 's being the substance that it is" (p. 170).
} 
As Siaotáoeıs concernem ao campo do físico na medida em que ele leva em conta os aspectos excluídos pelo matemático em seu procedimento de abstração. É preciso, portanto, compreender as $\delta$ ıootó oєıৎ enquanto propriedades de um ente suscetível à mudança.

No mesmo capítulo 2 de Física II, após retomar os conceitos de matéria [ữ $\eta$ ] e forma [EíSos] enunciados em 193a 28 e afirmar que cabe à ciência natural o estudo de ambos (194a 26), Aristóteles insere um modo causal que diz respeito apenas ao objeto do físico, quer se trate

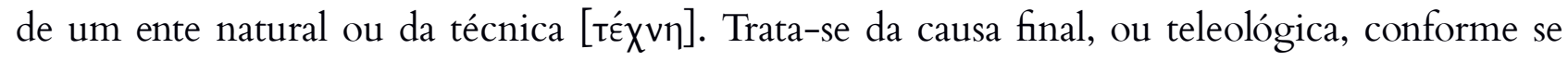
pode depreender, por exemplo, desta passagem:

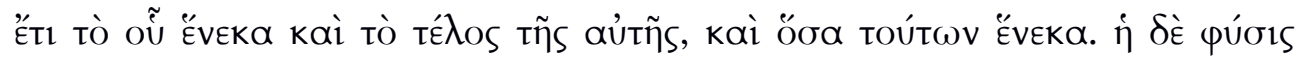

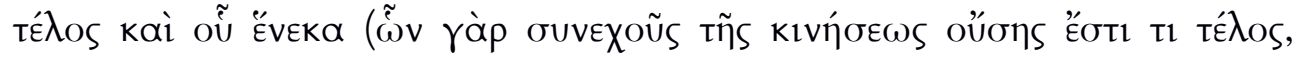

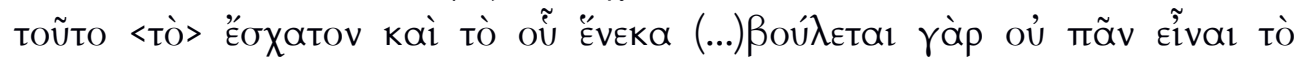

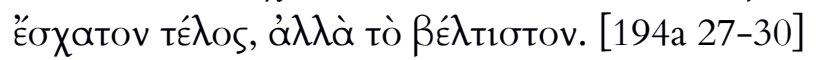

Além disso, compete a uma mesma ciência conhecer aquilo em vista de quê (isto é, o acabamento) e todas as coisas que são em vista daquilo. E a natureza é acabamento e aquilo em vista de quê (pois, das coisas de que há algum acabamento - havendo um movimento contínuo para tal - o acabamento é o extremo e aquilo em vista de quê; (...) ora não é qualquer extremo que se habilita a ser acabamento, mas sim o melhor).

Destacado das mudanças a que a matéria está submetida, o objeto matemático não participa de um 'movimento contínuo' para uma dada completude. Tanto a matéria do objeto da técnica quanto o ente natural estão submetidos aos movimentos que caracterizam suas completudes. No primeiro, como explica Aristóteles um pouco abaixo, o em vista do quê atua na matéria, no momento da produção, selecionando a configuração necessária tendo em vista um determinado fim, e também sob a forma, no momento do uso de tal objeto, isto é, selecionando o melhor modo de execução da função que caracteriza tal objeto. Assim, a causa final atua tanto na produção do objeto, numa dada matéria, quanto na sua execução, numa dada forma.

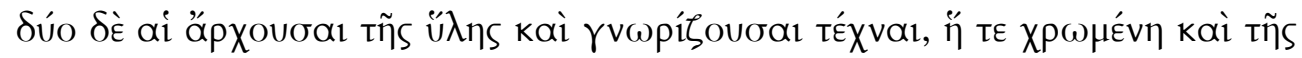

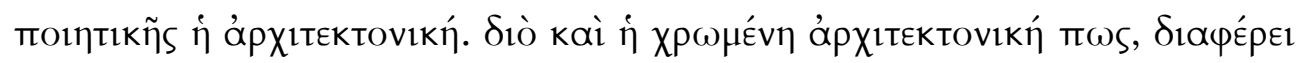

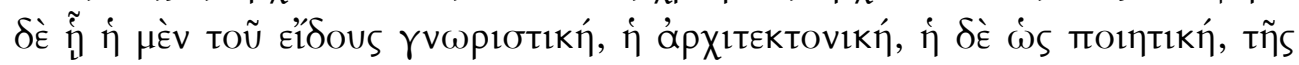

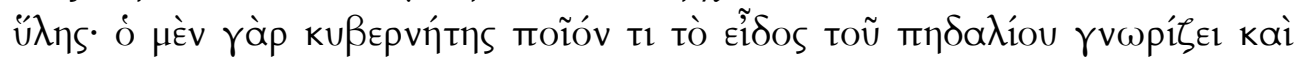

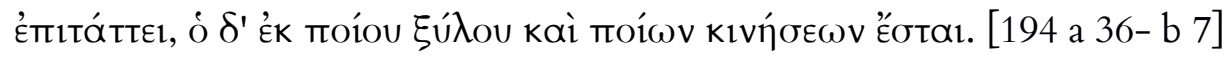


São duas as técnicas que conhecem e dominam a matéria, a que usa e a que comanda na técnica fabricante. Por isso, também a técnica que usa de certo modo comanda, mas há diferença na medida em que ela é conhecedora da matéria. De fato, o piloto conhece e prescreve de que qualidade é a forma do leme, ao passo que o outro sabe de qual madeira e de quais movimentos há de provir um leme.

Entretanto, Aristóteles contrapõe esses modos de atuação da causa final ao modo como ela atua nos seres naturais. Se, sob os primeiros, somos nós que ora estabelecemos a forma adequada para um fim ora somos a causa final ao utilizarmos os objetos [194a 34]; com os entes naturais, a causa final se estabelece internamente e diz respeito às ações que definem tal ente, isto é, às suas funções: "Naquilo que resulta da técnica, somos nós que fazemos a matéria ser em vista da função, ao passo que, nos entes naturais, a matéria já se encontra dada em vista da função" [194 b7].

Assim, a causa final funciona como norteadora dos movimentos que caracterizam o composto de forma e matéria, e que, portanto, é determinante em relação às propriedades que caracterizam o ser vivo. Deste modo, a teleologia exerce um papel - ausente nos entes

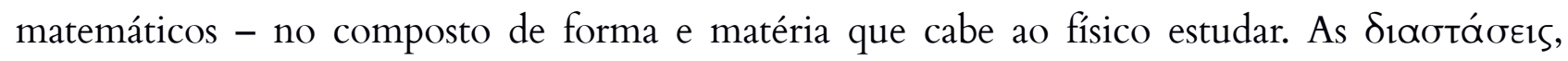
então, enquanto propriedades do corpo enquanto corpo natural suscetível de mudanças, participam de algum modo do caráter funcional da organização desse corpo. Como será visto

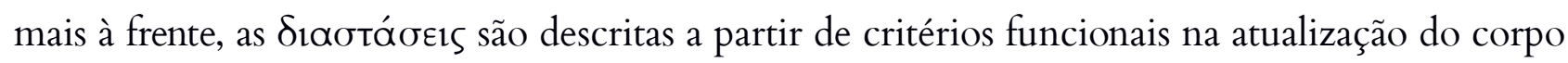
animado.

Deste modo, a teleologia, que, como Aristóteles afirma em Met. B 2, 996a 21s, se aplica somente à física - distinguindo-se portanto da matemática - possui papel fundamental nas

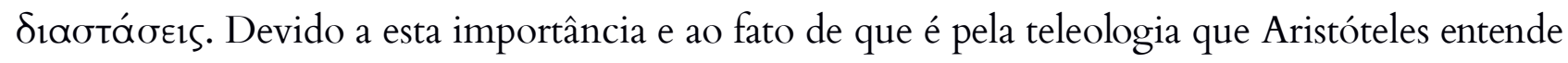

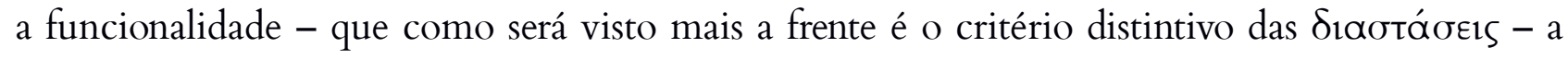
teleologia será tratada mais detalhadamente.

\section{Notas sobre a teleologia em Aristóteles}

O modo mais usado por Aristóteles para se referir à causa final é através da expressão em

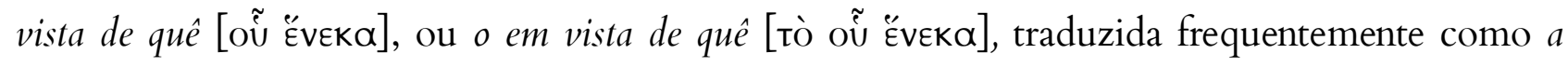
causa em vista de algo. Entretanto, há outros termos que também são usados pelo Estagirita para

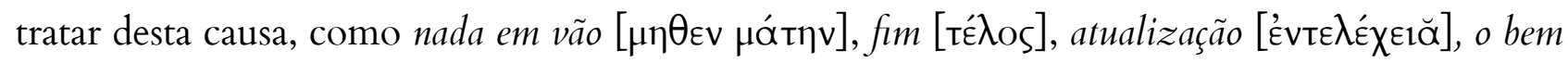

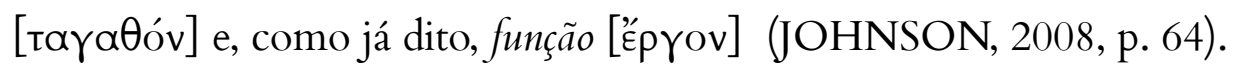


Apesar de existirem inúmeros modos de referência a esta causa, não há nenhuma definição explícita dela em todo o corpus aristotelicum (GOTTHELF, 1987). O que há são inúmeras passagens que apontam a causal final em algum fenômeno, fazendo uso de algum dos termos citados acima.

Tomemos como exemplo Física II 7. Esta é uma das passagens em que Aristóteles enumera as causas e utiliza a expressão mais comum para enunciar a final:

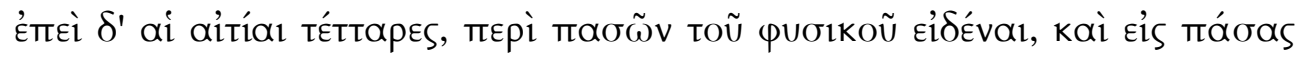

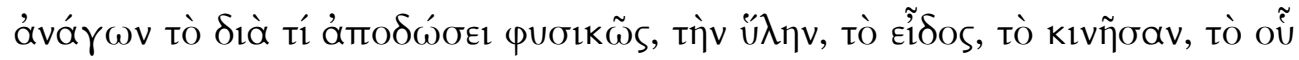
ËveKa. [198a 22-23]

Uma vez que as causas são quatro, compete ao estudioso da natureza conhecer todas, e ele há de explicar o porquê de maneira própria à ciência natural na medida em que se reportar a todas elas, a matéria, a forma, aquilo que moveu, aquilo em vista de quê.

Num trecho um pouco mais a frente, Aristóteles dá alguns exemplos do que seriam estes em vista de algo na natureza.:

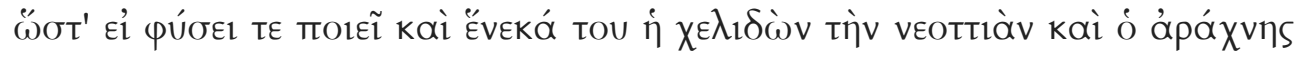

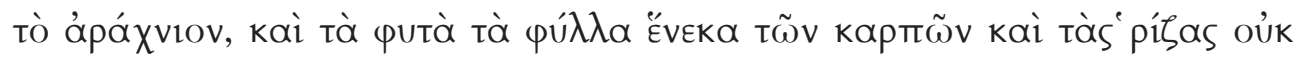

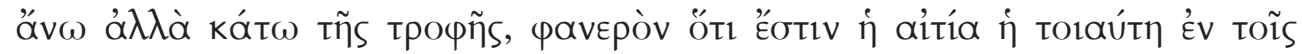

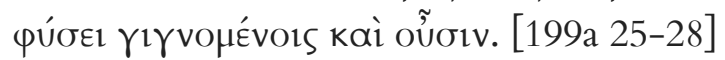

Por conseguinte, se é por natureza e em vista de algo que a andorinha faz ninho, a aranha faz a teia, bem como as plantas fazem as folhas em vista dos frutos, e as raízes para baixo, não para cima, em vista do alimento, é manifesto que há uma causa de tal tipo nas coisas que vêm a ser e são por natureza.

Apesar de não indicar a finalidade específica do ninho nem da teia nessa passagem, a existência das folhas e a posição das raízes para baixo é explicada tendo em vista um para quê, um objetivo que é benéfico e muitas das vezes essencial à manutenção da vida do ser vivo. Falar do em vista de algo é, portanto, falar de um fim que orienta a existência de determinada propriedade, isto é, para algo que se tem em vista, seja um produto ou uma atividade, certas coisas são necessárias e é nessa necessidade, estabelecida pelo fim, que se encontra o valor explicativo desta causa: isto e isto existem e são assim por causa de tal fim. Daí télos também ser um termo usado por Aristóteles para exprimir a causa final. 
Entretanto, é importante ter bastante cuidado com este fim. Ao menos duas ressalvas se fazem necessárias: (i) não se trata aqui de um fim extrínseco ao ser vivo, (ii) nem se trata de uma causa almejada como que deliberada ou pensada (com exceção de algumas ações específicas). Vejamos melhor cada um delas.

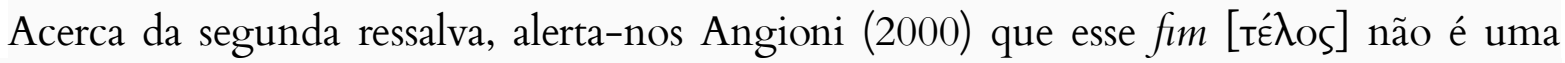
animização da natureza, que ele chama de "psicologização da natureza", isto é, Aristóteles não atribui à natureza uma espécie de mentalidade que estabelece finalidades aos entes, nem atribui aos entes naturais uma certa racionalidade para escolher seus fins. Trata-se de um fim que não é extrínseco à própria coisa, mas interno, no sentido de completude de acabamento do próprio ente. Em outras palavras, é um fim que é a própria efetivação do que caracteriza o ser. Para atingir o conjunto de características que o definem enquanto tal certas condições são necessárias, tal como a planta precisa de raízes para baixo, já que sua nutrição vem da terra, ou como o

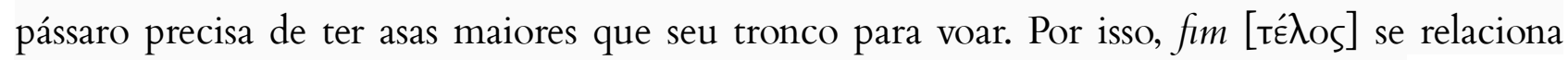
com duas outras palavras também usadas por Aristóteles ao falar sobre a causa final: atualidade

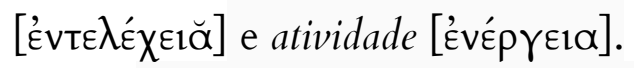

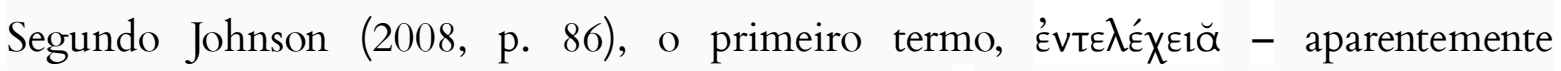
neologismo do próprio Aristóteles, cujo radical vem de tédos - é tradicionalmente traduzido por

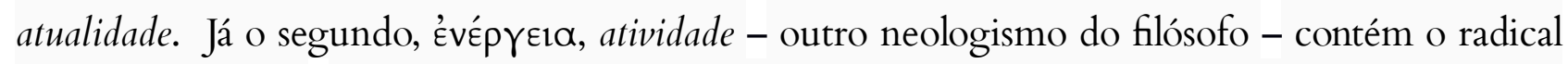
de Éprov, função - termo este que já era usado em significado técnico no tempo de Platão.

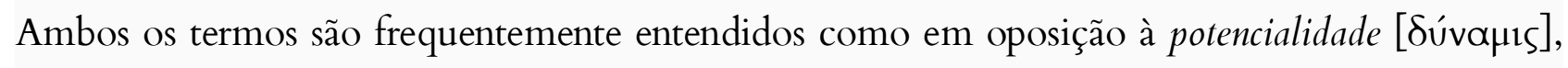
e muitos, de fato, os tomam como sinônimos em muitos contextos ${ }^{27}$. Entretanto, como Johnson (2008) nos alerta, é difícil imaginar que Aristóteles criaria dois novos termos tendo apenas um conceito em mente. Não exporemos aqui todos os pormenores que os diferenciam, mas uma passagem em Metafísica IX 8 é extremamente elucidativa, pois relaciona todos os conceitos referidos até aqui: "A função é o fim, e a atividade é a função. Por essa razão a palavra atividade é

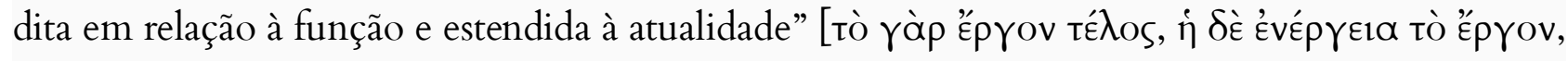

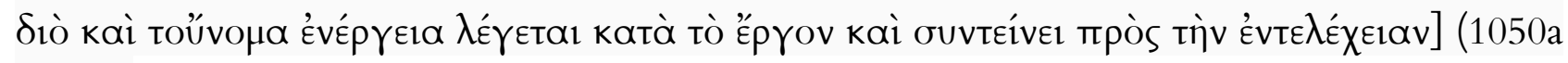
21-23).

Se entendermos éprov do mesmo modo como vimos acima em $I A$, como função ou

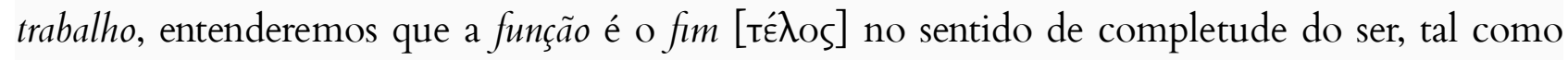

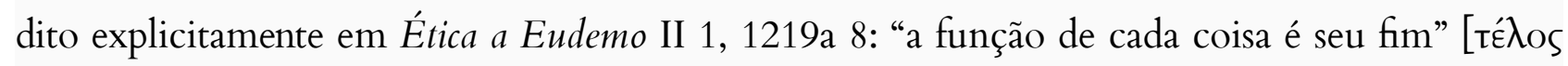

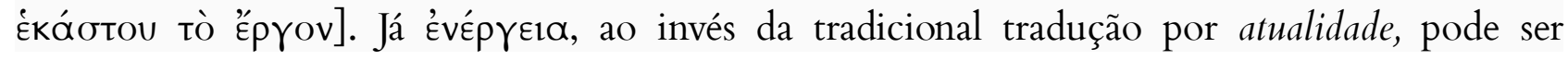

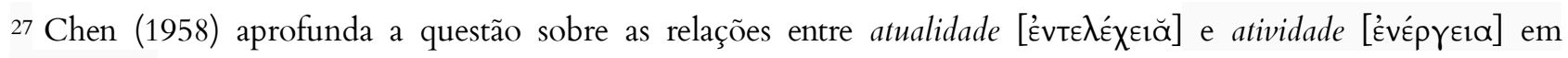
Aristóteles. 
entendida no sentido de 'estar em ação, ou em exercício', tradução esta que adotamos ao entendermos tal conceito como sendo um estado de érgon, tal como afirma Johnson (2008, p. 90).

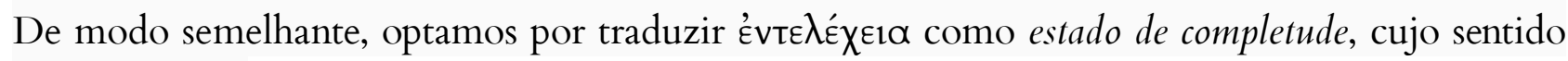
se une a té̀̄os.

Estar na efetividade da função, évép

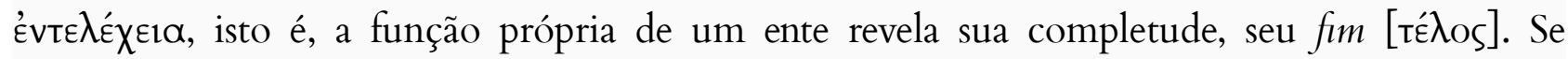
deliberar é a função própria do homem, tal como é dito em Ética a Nicômaco 1098a 6-18, o

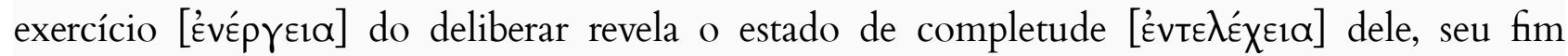

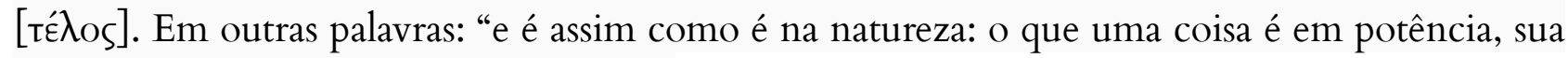

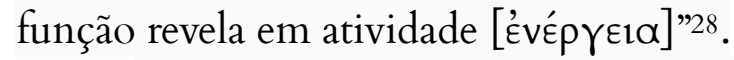

A completude do ser se mostra na atividade que o caracteriza, sua função. A teleologia, portanto, tem um papel importantíssimo na definição dos seres vivos, pois eles serão definidos em relação à atualização efetiva de suas funções, como é exaustivamente exposto por Aristóteles em Física II e em PA I, ao tratar do papel da teleologia no composto de matéria e forma.

O livro II da Física começa justamente pensando em como se dá a relação entre matéria e forma, em que ambas são entendidas como natureza de um ente. Já em Metafísica A, Aristóteles lidara com a relação entre as causas materiais e formais, apontando a supervalorização da matéria nos fisiólogos. O modelo de explicação do 'achatado' é justamente uma tentativa de explicar a relação de forma e matéria. Porém, apresenta uma insuficiência na resolução do problema, já que a relação forma-matéria ou nariz e forma não resulta numa relação de necessidade entre ambos os termos, isto é, de um não se resulta outro, e, portanto, gera uma predicação não-essencial entre as naturezas (ANGIONI, 2000).

Será a comparação entre natureza e técnica (“a técnica imita a natureza” c.f $P A$ I e Física II), introduzida no livro II da Física, que Aristóteles resolverá o problema desta relação, refutando não só o reducionismo material e o formalismo platônico, mas também refutando uma possibilidade hilemórfica que fosse pautada numa relação de independência (achatado) ou de indivisibilidade entre os termos. Essa resolução se dá pela teleologia.

Tanto na técnica como na natureza, seriam idênticos os nexos de estrita necessidade entre o té $\cos$ (a forma do artefato a ser produzido, o acabamento do organismo vivo) e suas condições de realização (ANGIONI, 2000, p. 153).

${ }^{28}$ Ética a Nicômaco 1168a 8-9. 
Assim, contra uma leitura "geometrizadora" do plano formal da natureza e corroborando o modo aristotélico de ver a forma como inseparável da matéria nos seres vivos, pode-se observar como em PA I 640b a 641a Aristóteles está preocupado em não elencar a forma [норфи́] como parâmetro suficiente para a definição de um ente. Neste trecho, o Estagirita critica Demócrito por julgar a forma [ $\mu о \rho \varphi \eta ́]$ como causa essencial na formação dos entes:

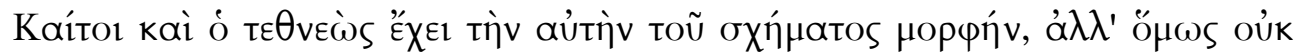

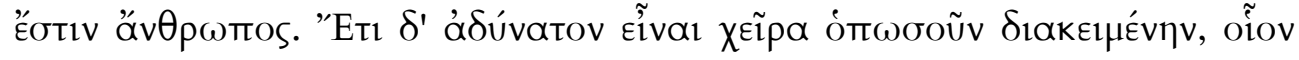

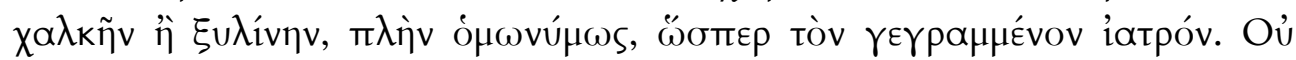

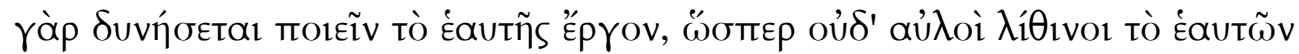

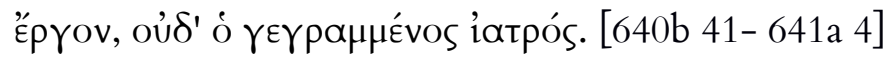

No entanto, um cadáver tem a mesma forma exterior e não é um homem. Do mesmo modo que é impossível que exista uma mão feita de um material qualquer - bronze ou madeira - a não ser por homonímia, ou um médico numa representação gráfica. Pois tal mão seria incapaz de desempenhar o seu papel, como flautas de pedra ou o desenho de um médico os que deles se espera.

Apesar de um cadáver possuir os mesmos traços e formas que um homem vivo, eles não são ditos por ninguém como sendo o mesmo, tal como uma mão feita de bronze ou madeira não é chamada mão propriamente dita. A explicação vem no final: nem o cadáver nem uma mão de madeira ou de bronze podem exercer as mesmas funções que um homem e uma mão de carne e osso, respectivamente. O que caracteriza, portanto, estes dois exemplos - não por acaso ambos dizem respeito a um ente natural ${ }^{29}$ - é a possibilidade de exercerem o que os define enquanto tais: a mão destinada a pegar coisas e o corpo em função da alma inexistem num cadáver.

Essa impossibilidade de definição tendo em vista apenas o aspecto formal ( $\sigma \chi \mathfrak{n} \mu \alpha)$ está respaldada também na própria definição de ente natural como encontrada em Física II: "coisas que possuem em si mesmo um princípio de movimento e mudança"30.

Acerca da crítica de Aristóteles aos predecessores em PA I, especificamente a Demócrito, comenta Carbone (2011, p. 96):

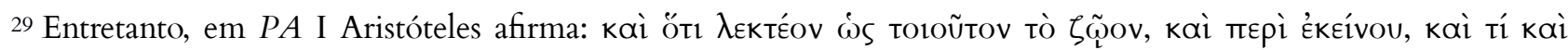

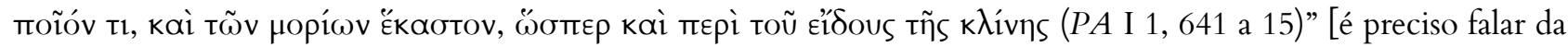
natureza de um animal, do que ele é, das suas qualidades e de cada uma das suas partes, como se faz ao falar-se da forma de uma cama].

${ }^{30}$ Física II 192b 12.
} 
O que a explicação de Demócrito não pode compreender é, portanto, a aptidão das partes de preencher uma função própria, porque essa aptidão evidencia ao mesmo tempo a forma e a matéria, pois é preciso que todas as duas sejam apropriadas para a atividade que cada parte do corpo deve exercer ${ }^{31}$.

Este trecho de $P A$ I tem fundamento, portanto, numa concepção teleológica de ser vivo. Como fica evidente ao longo de todo o livro I de $P A$, o "para quê", ou a causal final, é a causa norteadora dos processos naturais e, deste modo, é ela que direciona primeiramente a forma. Não por acaso também é elencada por Aristóteles como a primeira causa ${ }^{32}$ : "A primeira parece ser aquela que implica o 'para quê' de um processo, ou seja, a sua razão de ser, que é um

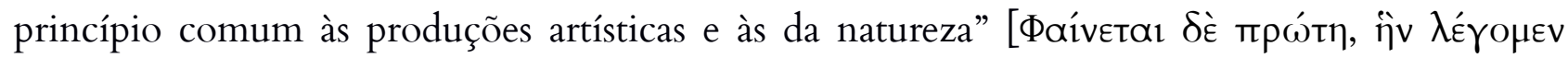

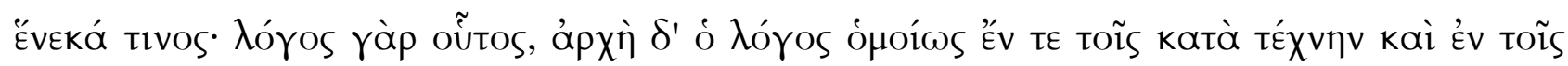

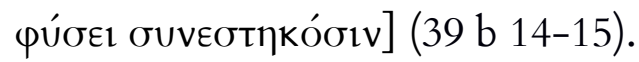

Teleologia esta que é sintetizada em 641 b1 no mote "a natureza faz todas as coisas em

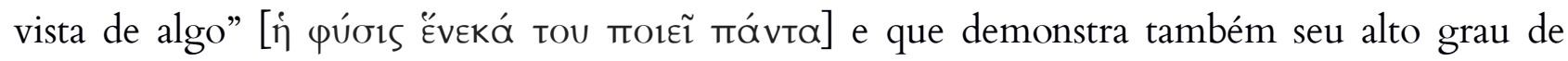
importância numa expressão correlata em $I A$ 2, elencada como premissa para a pesquisa natural, como visto linhas acima33. Pode-se dizer, portanto, que em ambos os textos $-I A$ e $P A-$ a finalidade está presente como premissa explícita e primeira, servindo de base argumentativa necessária para a interpretação das demais: no $I A$ para a segunda e terceira premissas e em $P A$ para o conceito de necessidade condicional ${ }^{34}$.

É importante notar aqui que, ao sustentar que a forma não é critério suficiente para descrever a essência de algo, Aristóteles utiliza o termo grego $\mu о \rho \varphi \eta^{35}$. É necessário sublinhar isto, pois linhas anteriores ao trecho citado de $P A$, Aristóteles, ao se referir à natureza de uma cama, diz que "de facto, a natureza "formal' é mais relevante do que a natureza "material"'36

\footnotetext{
31 Ce que l'explication de Démocrite ne peut pas saisir, c'est donc l'aptitude des parties à remplir une fonction propre, du fait que cette aptitude relève en même temps de la forme et de la matière, car il faut que toutes les deux soient appropriées à l'activité que chaque partie du corps doit exercer.

32 Entendemos primeira aqui como uma prioridade metodológica e não necessariamente ontológica ou cronológica. 33 A primeira premissa do $I A$ guia de fato todo o estudo dos seres vivos, pois esta não só tem grande recorrência nos textos aristotélicos - como lista Lennox (2001), que faz um estudo pormenorizado acerca de sua ocorrência e de outra correlata -, mas também possui muita importância devido ao seu caráter teleológico, característica preponderante no estudo aristotélico dos seres vivos.

${ }^{34}$ Sobre necessidade e teleologia em $P A$, c.f Balme (1987).

${ }^{35}$ Para uma discussão mais aprofundada sobre o assunto, também é necessário considerar conceitos como schéma, que frequentemente vem junto com morphé (c.f: Física II 2, 193b 31-32).

36 Tradução de Maria de Fátima Sousa e Silva.
} 


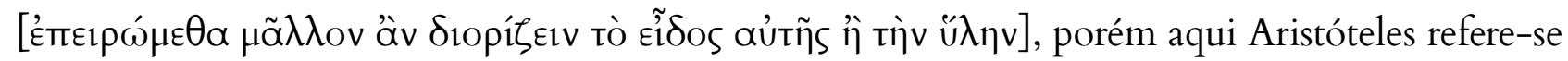

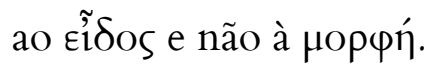

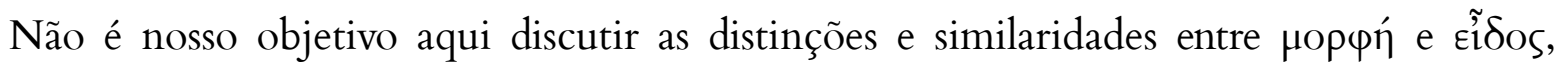
assunto este que não alcançou unanimidade nem entre os grandes comentadores ${ }^{37}$, porém no que diz respeito ao menos a essas passagens podemos concordar com Long (2007, p. 2) ao dizer que "morphé designa a forma enquanto inseparável da matéria na qual ela é inerente, enquanto eídos, por ser mais facilmente separado da matéria, é o vocabulário usado para determinar a forma como o princípio ontológico do composto individual"38.

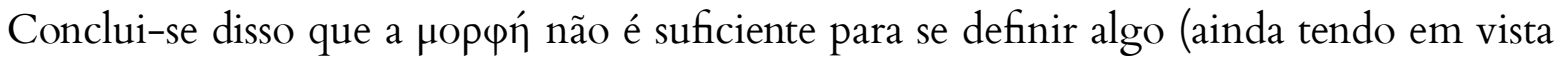
a crítica a Demócrito em $P A)$, pois “cada animal e suas partes tem uma estrutura teleologicamente unificada de acordo com o fim supremo numa maneira hierárquica"39 (CHATANI, s/d), fim supremo este que é a perpetuação de cada espécie, como atesta Aristóteles em De Anima II 415b 1 (ANGIONI, 2000).

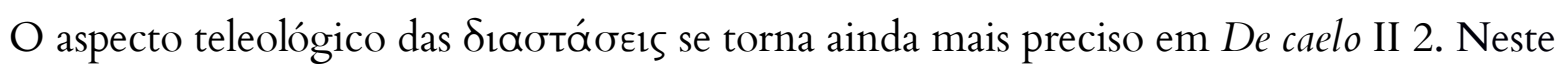

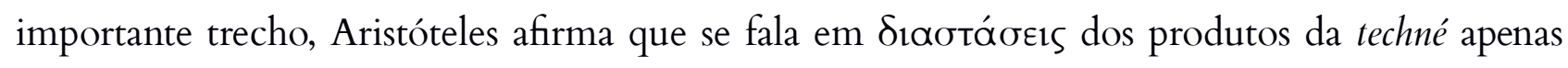
por analogia aos corpos naturais ${ }^{40}$, já que somente estes últimos possuem-nas de fato ${ }^{41}$. $\mathrm{O}$

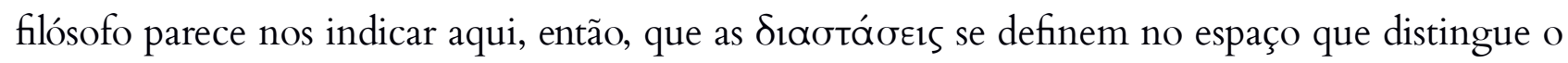
ente natural do ente oriundo da técnica:

\footnotetext{
${ }_{37}$ Um quadro geral sobre esse assunto pode ser encontrado em Long (2007).

38 "morphe designates the form as inseparable from the matter in which it inheres, while eidos, because it is more easily separated from matter, is the vocabulary used to determine form as the ontological principle of the composite individual."

39 "each animal and its parts have unified teleological structure under the supreme end in a hierarchical manner."

40 Aristóteles parece fazer menção nesta passagem à divisão estabelecida em Física II entre os entes naturais e os oriundos da técnica.

41 "Somos nós mesmos o referencial para isso. Quando falamos de acima e abaixo, ou direito e esquerdo relativamente a essas coisas [produtos da tekhné], a referência pode ser à nossa própria mão direita, como com aqueles que pronunciam oráculos, ou por analogia com nossa própria configuração corpórea e como quando falamos da direita da estátua; ou podemos preferir a ordem espacial oposta, chamando de direito aquilo que está à nossa esquerda, e de esquerdo o que está à nossa direita. Distinção alguma, porém, é percebida por nós nas próprias coisas; realmente, se são giradas, as partes opostas passam a ser designadas por nós de direita e esquerda, acima e

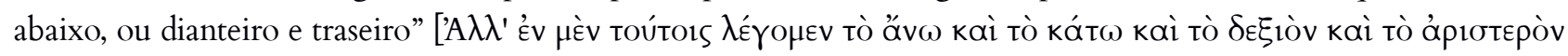

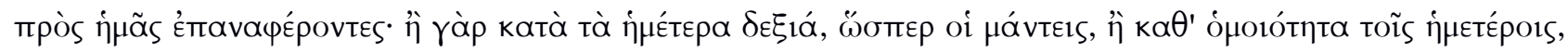

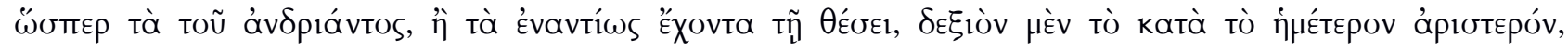

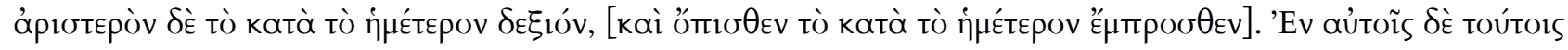

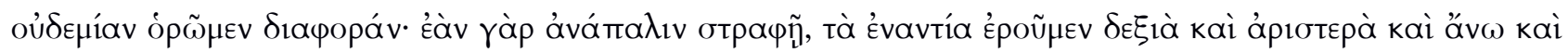

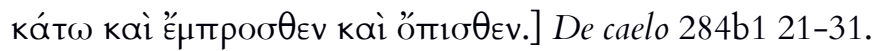




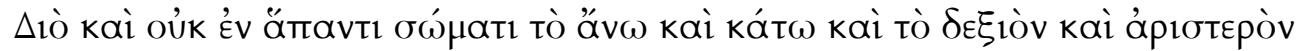

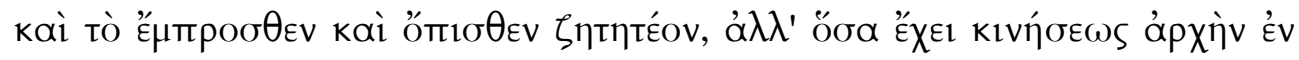

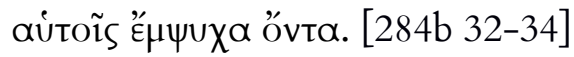

A conclusão é que o alto e o baixo, a direita e a esquerda, a frente e a traseira não devem ser procurados em todos os corpos, mas somente naqueles que, por serem animados, encerram no interior de si próprios um princípio de movimento.

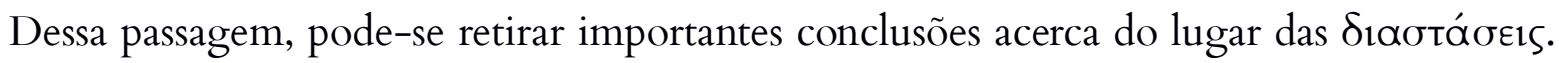

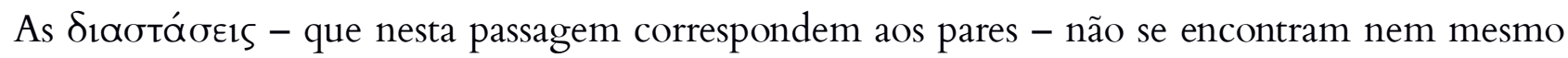
nos objetos da técnica, isto é, em entes que possuem forma e matéria em sua constituição. Como visto acima, a teleologia possui um papel importante na constituição do composto, mas

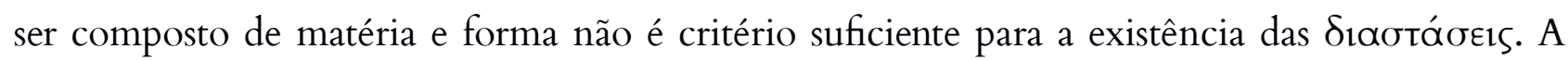

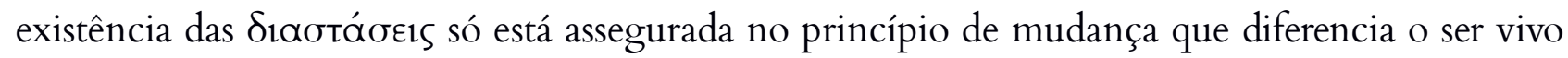
do ente da técnica: a alma.

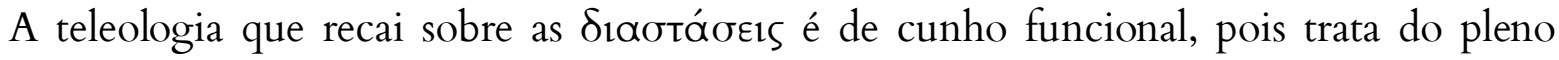

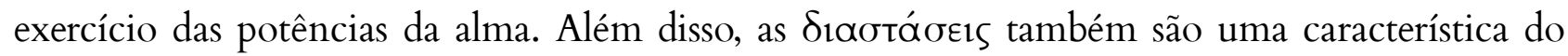
corpo animado, enquanto propriedade geométrica dele, isto é, são os limites [ $\pi \varepsilon ́ p a \varsigma$ da grandeza do ser vivo, que, como visto em Física II 2, cabem ao físico estudar.

Move-nos, a partir desse ponto, a indagação acerca da relação entre a uuxú e as

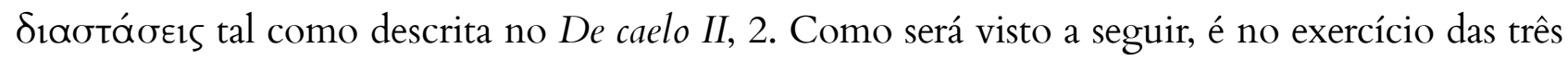

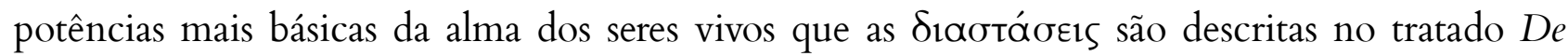
Incessu animalium. O que num primeiro momento poderia ser dito de um âmbito unicamente geométrico, passou ao estudo do físico na medida em que se trata de uma propriedade geométrica do corpo que de algum modo se funda na alma e se encontra manifesta, em seus pares, sobretudo no corpo do homem.

\section{As Sıaбtáoєıৎ no De incessu animalium}

Antes mesmo de enunciar as três premissas que nortearão o estudo no $I A$ - entre elas as

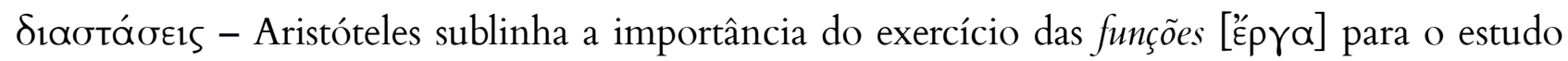
dos fenômenos naturais. Nesse trecho, entretanto, optou-se por traduzir épra por atividades ${ }^{42}$,

\footnotetext{
${ }^{42}$ Farquahrson (1915) traduz o sintagma por "all Nature's work" e Morel (2013) "dans toutes les opérations de la nature".
} 
pelo fato de que este termo parece melhor exprimir aqui as nuances do conceito no que diz respeito à atualização da funcionalidade dos entes da natureza.

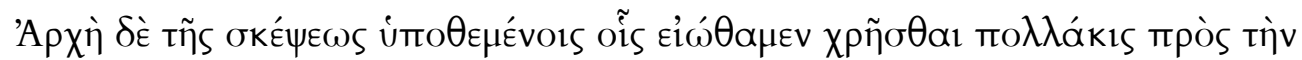

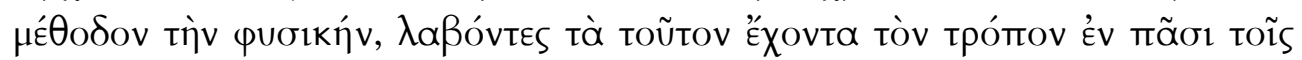

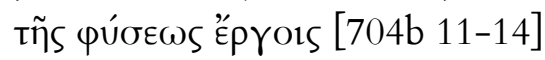

Para o princípio da pesquisa devemos assumir as premissas que estamos regularmente acostumados a usar na investigação natural, isto é, tomar por certo o que ocorre de acordo com elas em todas as atividades da natureza [ró vta tà

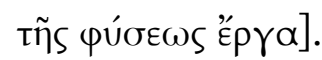

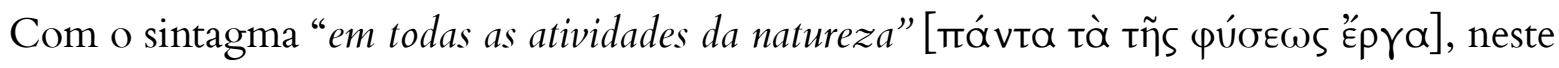
contexto pré-enunciatário das premissas do $I A$, Aristóteles parece apresentar uma necessidade metodológica para os estudos dos seres vivos, pois, como visto anteriormente, é só a partir da atualização do ser natural que se pode dizer o que ele é43. Além disso, este passo é de extrema

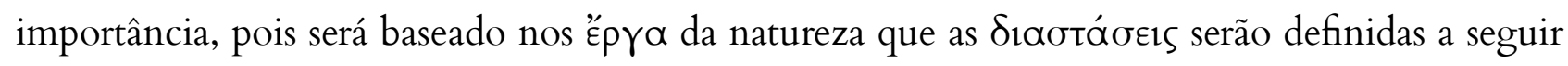
no texto. Como sublinha Morel (2013) acerca do objetivo do IA na introdução de sua edição, "Não se satisfazer com um catálogo das particularidades, não perdê-las mais na abstração, mas compreender seus princípios explicativos através das “operações da natureza” ${ }^{44}$.

É no capítulo quatro do De incessu animalium que Aristóteles descreve mais

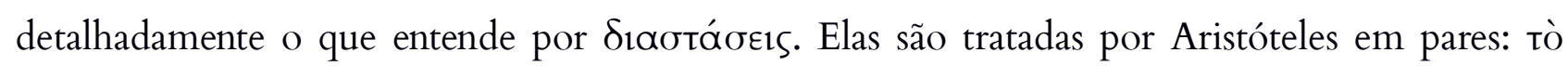

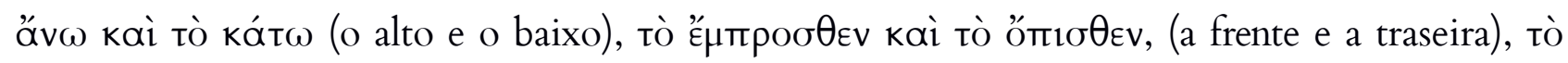

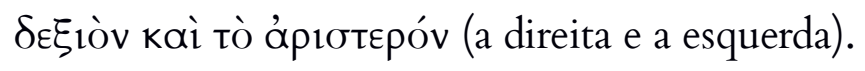

Sobre o primeiro par, o filósofo afirma que todos os seres vivos possuem uma parte superior e uma inferior, tanto plantas quanto animais. Ao colocar ambos os seres naturais em comparação, Aristóteles reapresenta a distinção que será o critério usado também para distinguir os demais pares, a função [Е́prov]: "Não somente há o alto e o baixo nos animais, mas também nas plantas. Porém eles se distinguem na função e não somente na posição em relação à terra e

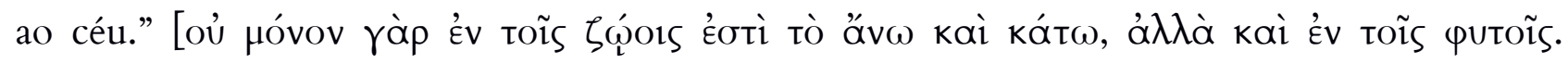

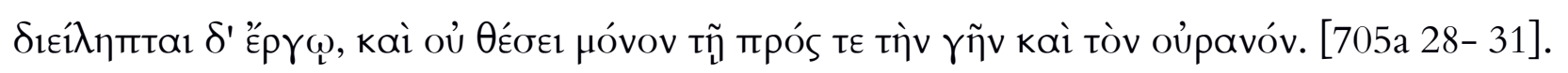

\footnotetext{
43 Física II 193a 35.

44 “Ne pas se satisfaire d'un catalogue des particularités, ne pas les perdre non plus dans l'abstraction, mais saisir leurs principes explicatifs au travers des "opérations de la nature".
} 
Em seguida, Aristóteles, baseado novamente na função, define o alto: "De onde vem a distribuição de nutrição e o crescimento em cada um é o alto; onde esta termina, o extremo, é o

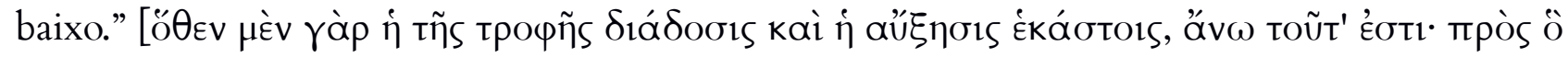

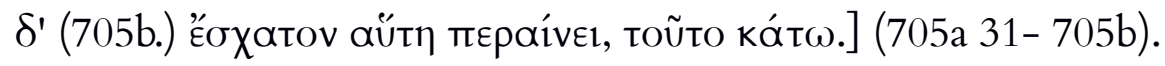

Aristóteles pode assim afirmar que as raízes são o alto para a planta e a boca para o homem, já que estes são os locais onde tais funções se iniciam. Além disso, por serem definidos em relação a estas funções ('́p $\gamma \alpha$ ) é que o alto e o baixo existem necessariamente em todos os seres vivos, pois estas duas funções são de fato o que caracterizam vida nos corpos naturais, segundo De Anima II 412a 14: "Por vida entendemos auto-nutrição e crescimento (...)”.

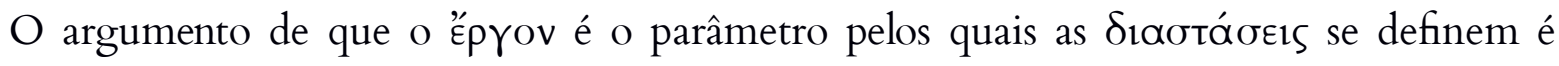
novamente repetido por Aristóteles ao afirmar que, apesar de o alto e o baixo não possuírem a mesma posição nas plantas e nos animais, eles possuem uma relação pelo fato de exercerem a mesma função: "Embora não estejam em igual posição em relação ao universo, eles estão em

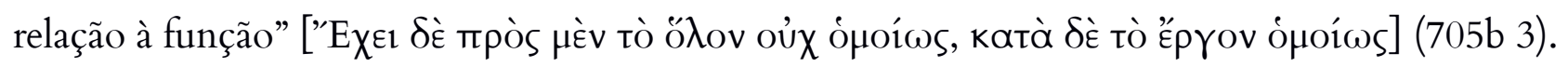

Em seguida, Aristóteles prossegue na definição dos demais pares. A frente e a traseira pertencem somente aos animais, já que as plantas não possuem a função que distingue as duas

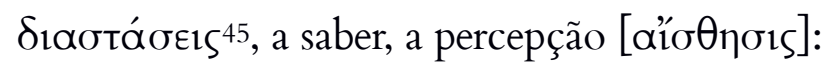

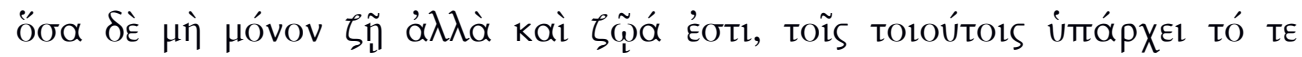

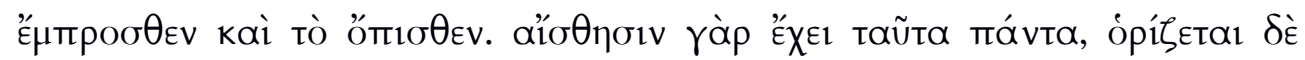

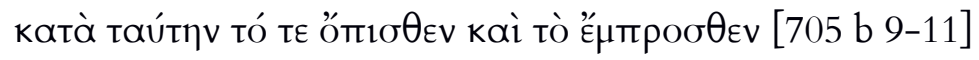

Os que não somente estão vivos, mas são animais, tanto a frente quanto a traseira os pertencem. Todos estes têm a percepção e, segundo ela, é definida tanto a traseira quanto a frente.

E, por fim, mas não menos importante, Aristóteles distingue a direita da esquerda tendo em vista a capacidade de se realizar uma mudança de lugar por si próprio, isto é, realizar um deslocamento. A direita é, então, estabelecida como o lugar onde começa a mudança de lugar e a esquerda como seu oposto natural: "De onde é o princípio natural da mudança de lugar, este é a

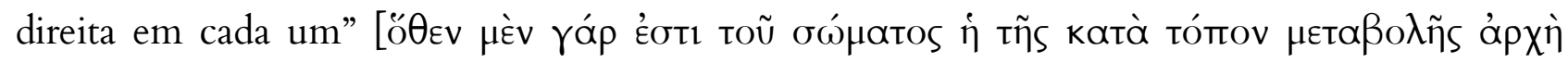

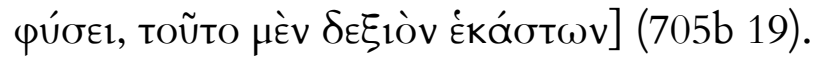

\footnotetext{
${ }^{45}$ Há nitidamente aqui uma taxonomia a partir das $\delta$ เơtáoøıs. Para mais detalhes acerca desse ponto, c.f Carbone (2011).
} 
Significativamente, o filósofo retoma o argumento da distinção baseada no éprov reafirmando que a distinção entre direita e a esquerda, tal como as anteriores, será fundada neste conceito: "Tal como os mencionados anteriormente, cada um deles é diferenciado em uma

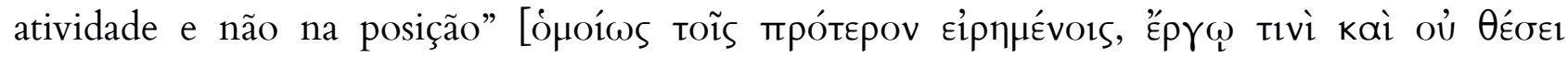

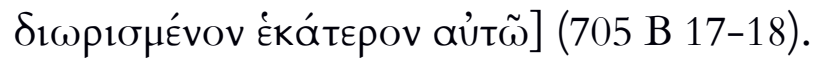

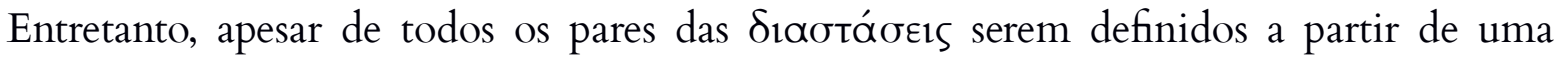
função natural, o alto e o baixo são distinguidos também em relação à posição do universo (LENNOX, 2009). Aristóteles distingue no capítulo 5 o alto dos seres vivos em relação a três partes do universo (tò óhov): o alto, o intermediário e o baixo.

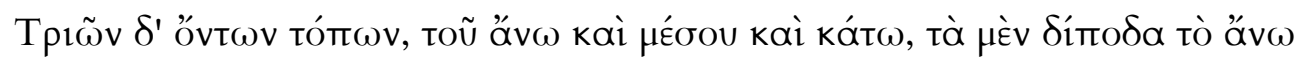

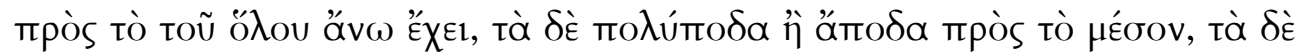

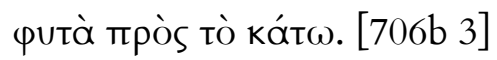

Os lugares são três: o alto, o médio e o baixo. Os bípedes possuem o alto em correspondência com o alto do universo, já os polípedes ou os ápodes com o meio, e as plantas com o baixo.

Acerca da correspondência do alto dos bípedes com o do universo, Aristóteles explica no mesmo trecho que o alto do homem é mais de acordo com o universo do que o pássaro, por ele ser o mais natural dos bípedes (c.f 706b 8).

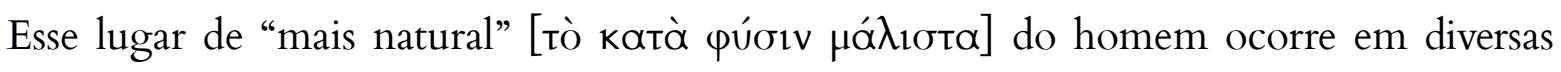
passagens no $I A$. No final do capítulo 4, Aristóteles, após afirmar que "os membros direitos no homem são mais direitos" do que os demais, conclui: "no homem os outros princípios

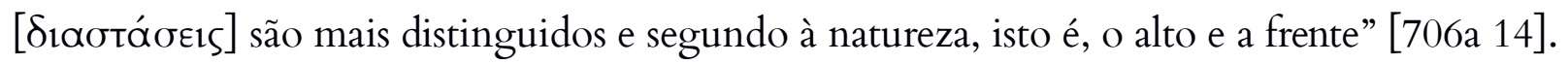

Uma opção para entender o maior grau de distinção desses princípios no homem é cotejá-lo com a metodologia proposta e seguida na História dos Animais I 491a 20, em que Aristóteles elege as partes do homem como ponto de partida para sua investigação:

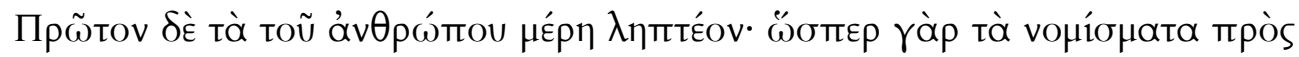

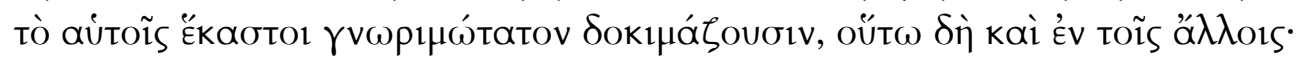

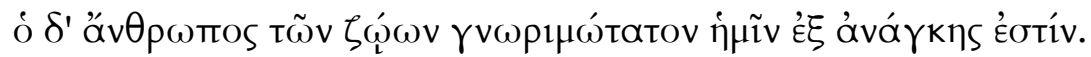

Antes de mais nada são as partes do corpo humano que importa estabelecer. De fato, da mesma maneira que cada povo estabelece o valor da sua moeda em face do termo de comparação que lhe é mais familiar, o mesmo se passa nos outros 
domínios. Ora o homem é, dentre os animais, aquele que por força das circunstâncias nos é mais cognoscível.

Se essa passagem parece resolver a questão das partes "mais distinguidas", em nada ela auxilia sobre a questão de o homem ser mais "segundo a natureza". Aristóteles parece corroborar esse tratamento em PA I 5, 644b 35, em que compara a proximidade do objeto da cosmologia com o da zoologia, apontando a vantagem do conhecimento das coisas terrestres: "além do mais, estas coisas estão muito mais perto de nós, elas são mais familiares e isso equilibra, em certa

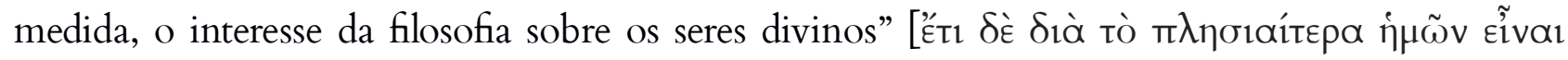

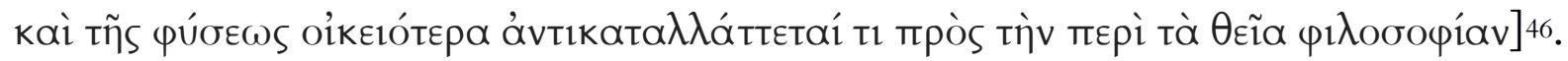

Além disso, Aristóteles se compromete mais ainda com esse modelo de referencial natural do homem no $I A$ ao justificar o porquê de a direita ser o princípio do movimento baseando-se

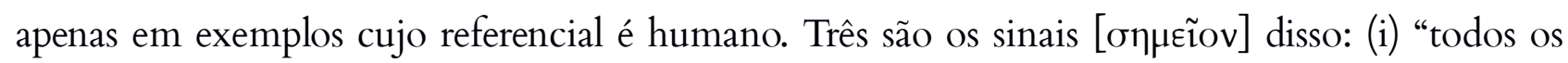
homens carregam os fardos no ombro esquerdo"; (ii) "todos os homens iniciam [o caminhar] com a esquerda"; (iii) "os homens se defendem com a direita”. Aristóteles explica cada um desses três pontos e, como já visto acima, justifica tendo em vista o fato de o homem ser mais segundo

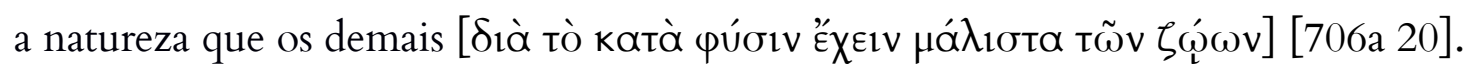

Essas justificativas de cunho antropocêntrico acerca da função de locomoção parecem sugerir uma segunda etapa de referência, isto é, se o homem é o modelo de referência, por conseguinte, também suas funções o são. Ou melhor: se é a partir do homem que se deve iniciar o estudo das partes dos seres vivos, devido à sua familiaridade, do mesmo modo se deve agir para com as funções essenciais que caracterizam um ser vivo.

O contexto da segunda definição de alma dada em De Anima II 1 413a 11-413b 13 corrobora essa segunda referenciação. Após ter enunciado uma definição para alma no início do mesmo livro II ("a alma é atualização primeira num corpo natural potencialmente com vida" 412a30), pautada em conceitos como atualização, potência e forma ("a substância formal é atualização" 412a 20), Aristóteles elabora uma outra definição trazendo agora os conceitos de

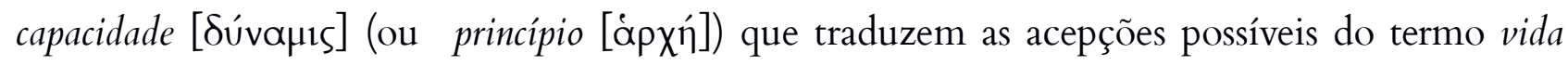

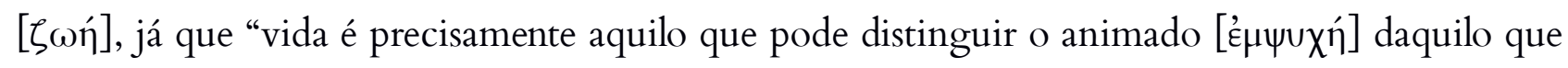

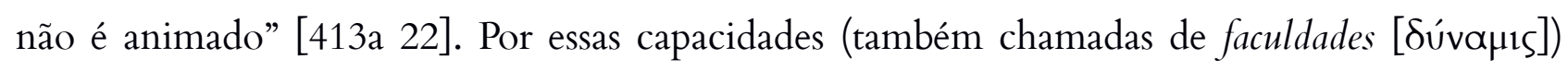
essenciais, Aristóteles tem em vista a nutrição, a sensação, o pensamento e o movimento:

\footnotetext{
${ }^{46}$ Sobre a ideia de "familiaridade" em Aristóteles conferir APo I 2, 71 b 19 e Fis I 1, $184 \mathrm{a} 16$.
} 


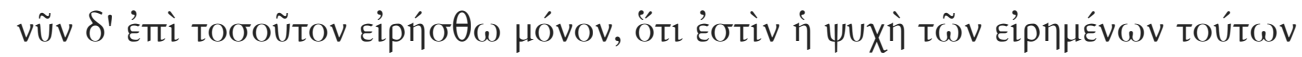

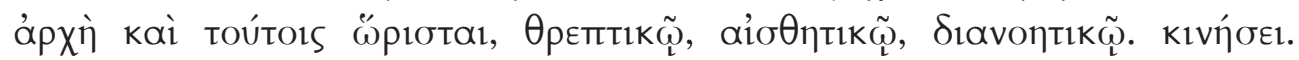
[413b 11]

Fiquemos, por agora, razoavelmente satisfeitos em afirmar que a alma é a origem das características acima mencionadas, além de ser por elas definida, a saber: pelas faculdades da nutrição, da sensação, do pensamento e do movimento.

A correspondência com $I A$ parece ser exata: Aristóteles afirma que a nutrição é o primeiro princípio natural, pois "esta capacidade de absorver alimento pode existir independentemente de todas as outras capacidades" [413a 30], como o que ocorre com as das plantas, que "não possuem elas, em relação à alma, qualquer outra capacidade" [413a 30]. Em seguida, Aristóteles elenca a primeira característica de um animal, que vai diferenciá-lo das plantas, a faculdade sensitiva [413b 1-2].

Interessa aqui sobretudo o contexto de transição entre a definição de 413a 11 e a de $413 b$ 11, isto é, como Aristóteles justifica um novo conceito de $\psi \cup \chi \eta ́$. É importante dizer que não se trata aqui de duas conceituações contraditórias ou excludentes, mas sim de dois modos distintos de Aristóteles descrever o mesmo objeto. É claro que o modo distingue o objeto, mas para Aristóteles aqui há uma complementaridade das duas conceituações, como fica evidente no contexto de introdução do último conceito:

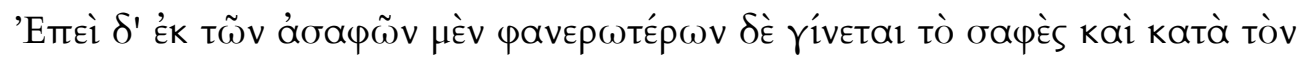

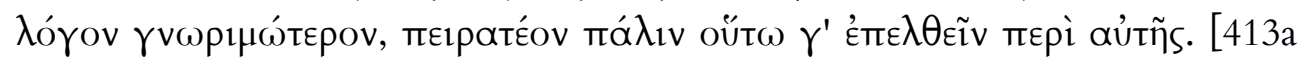
$11-13]$

Entretanto, como é das coisas mais evidentes mas incertas que surge o que é claro e mais cognoscível segundo a razão, é preciso novamente ir a ela deste modo.

Aristóteles aqui apresenta a necessidade de se elaborar uma concepção da alma que seja mais cognoscível [ $\gamma v \omega \rho \mu \omega ́ t \varepsilon \rho o v]$, que surja das coisas que são mais evidentes, como o conhecimento dos sentidos. E é exatamente este aspecto que diferencia a primeira conceituação da segunda, na medida em que Aristóteles introduz nesta última as funções da alma, já que estas

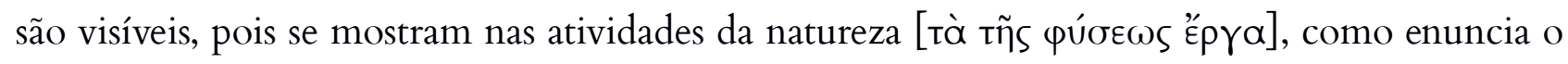

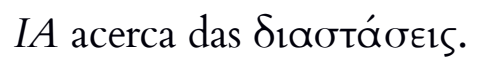




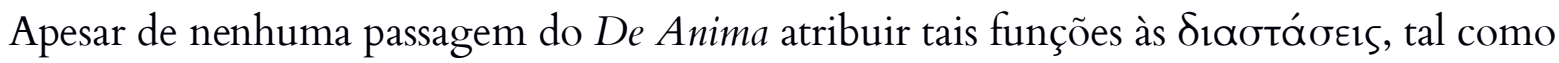
é feito no $I A$, as funções são introduzidas devido à necessidade de aproximação com o conhecimento sensível que, como visto acima, emerge primeiramente do que é mais próximo, mais familiar, isto é, da observação acerca do próprio homem.

Como as funções emergem dessa preocupação com o conhecimento sensível, isso parece justificar novamente a localização das funções em relação ao homem no $I A$. Em outras palavras, o fato de o alto ser para o homem o princípio da nutrição, a direita o princípio do seu caminhar e a frente o de sua percepção parece nortear a relação entre as funções e os eixos.

Já que o homem é ponto de partida para $H A$, as funções no De Anima, enquanto oriundas também de uma preocupação sensível, corresponderão a lugares que dizem respeito às funções do homem. O IA, portanto, parece expressar esse aspecto referencial do homem através de suas funções.

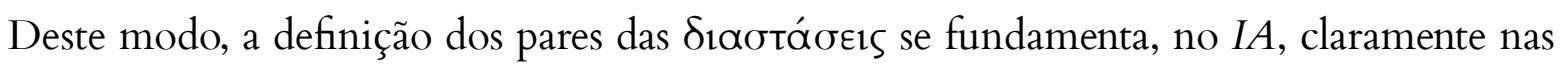
atividades que os seres vivos exercem. Entretanto, o aspecto formal, comentado nas primeiras linhas, também é encontrado no texto em questão.

Ao definir o alto como o lugar de onde vem a nutrição e o crescimento no ser vivo e ao

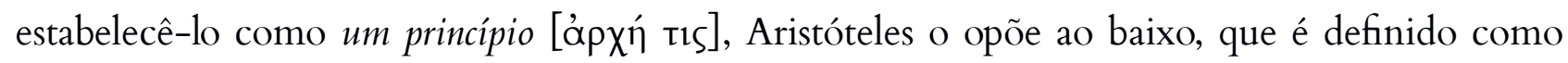

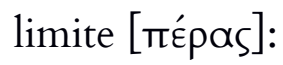

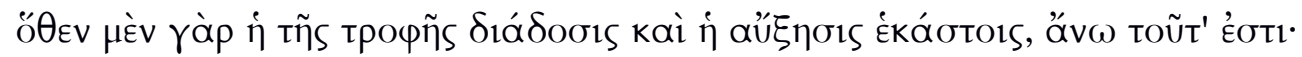

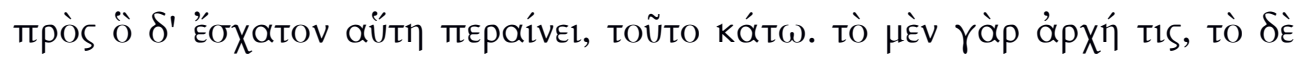

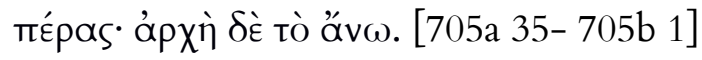

De onde vem a distribuição de nutrição e o crescimento em cada um é o alto; onde esta termina, o extremo, é o baixo. Um é um princípio e o outro limite: o princípio, porém, é o alto.

A função que define o alto só pode existir enquanto houver uma limitação de seu espaço. Esse limite formal, entretanto, não define os eixos direcionais. O que há aqui é uma

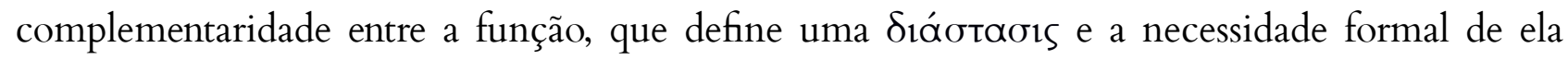
ocupar um espaço delimitado. A delimitação ocorre por causa da função, mas ela não existe num nível abstrato, ela existe, de fato, dentro dos limites que o corpo estabelece. 


\section{Conclusão}

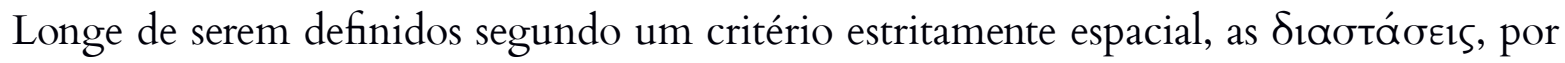
fazerem parte da constituição formal de um ser vivo, se atualizam nos corpos vivos a depender da existência de funções essenciais da alma. Entretanto, o caráter formal delas está presente na referência ao limite [ாદ́pas] e no fato de serem propriedades geométricas do corpo. Além disso,

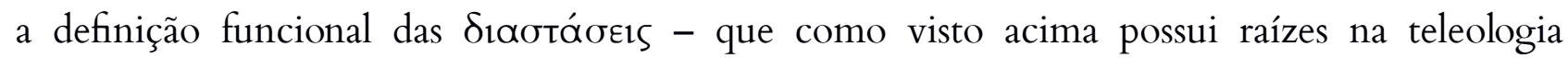
aristotélica - parece tomar o corpo humano como referência, tanto por considerá-lo o ser vivo mais cognoscível, tomando-o como ponto de partida da investigação, mas também devido ao teor antropocêntrico dos exemplos utilizados por Aristóteles para justificar os princípios das funções.

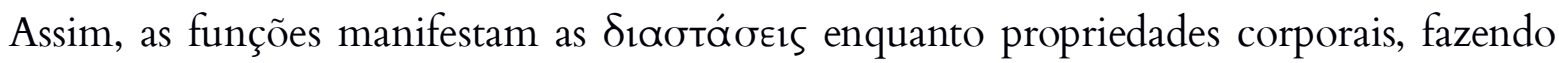
com que a estrutura do ser vivo seja justificada teleologicamente, mas ao mesmo tempo as escolhas dos princípios das funções não estão isentas de um referente. Os princípios das funções espelham as funções do homem, modelo de perfeição dos entes naturais e que se caracteriza, portanto, como referência de valor necessária à diferenciação das multiplicidades dos corpos naturais.

\section{Referências bibliográficas:}

A.GOTTHELF and J.G. LENNOX(eds) Philosophical issues in Aristotle's Biology. Cambridge: Cambridge University Press, 1987.

ANGIONI, Lucas. As noções aristotélicas de substância e essência. Campinas: Editora da Unicamp, 2008.

- "O hilemorfismo como modelo de explicação científica na filosofia da natureza em Aristóteles”. Kriterion, Belo Horizonte, nº 102, Dez/2000, pp. 136-164.

ARISTOTE. Traités des Parties des Animaux et de la Marche des Animaux. Traduction et notes par Barthélemy Saint-Hilaire. Paris: Hachette, 1885.

Le Mouvement des Animaux suivi de La Locomotion des Animaux. Introduction, traduction et notes par Pierre-Marie Morel. Paris: GF Flammarion, 2013.

ARISTÓTELES. De Anima. Apresentação, tradução e notas de Maria Cecília Gomes Reis. São Paulo: Ed. 34, 2006. . Metafísica. Tradução de Giovanni Reale. Vol. II. São Paulo: Edições Loyola, 2005. 
Física I \& II. Tradução, introdução e notas Lucas Angioni. Campinas: Editora da Unicamp, 2013.

ARISTOTLE. "Ethica Eudemia”. In: The Complete Works of Aristotle. Trad. J. Solomon. The Revised Oxford Translation. Ed. Jonathan Barnes. Princeton: Princeton University Press, 1984.

. On the Gait of Animals. Translated by A. S. L. Farquharson, Oxford, 1912.

Progressions of animals. Translated by A. L. Peck and E. S. Forster. Loeb classical library. Cambridge, MA: Harvard University Press.

BARTHÉLÉMY-SAINT HILAIRE, Jules. Traités des parties des animaux et de la marche des animaux. 2 vol. Paris: Hachette, 1885.

CARBONE, Andrea L. Aristote Illustré: Représentations du corps et schématisation dans la biologie aristotélicienne. Paris: Classiques Garnier, 2011.

. "The Axes of Symmetry. Morphology in Aristotle's Biology”. APEIRON, 49 (1), 2016, pp. 1-31.

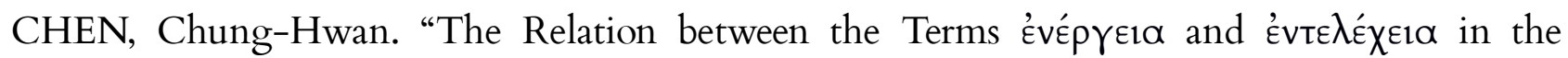
Philosophy of Aristotle”. The Classical Quarterly, New Series, vol. 8, n. 1/2 (May, 1958), pp. 12-17.

JOHNSON, M. R. Aristotle on Teleology. Oxford, 2008.

NUSSBAUM, Martha C. Aristotle’s De Motu Animalium. Princeton University Press, 1985.

LENNOX, J. "De caelo and Its Debt to the De incessu animalium". In: BOWEN, A. and WILDBERG, C. (eds.). New Perspective on Aristotle's De caelo. Leiden: Brill, 2009, pp. 187214.

LEAR, Jonathan. "Aristotle's Philosophy of Mathematics". The Philosophical Review, vol. 91, n. 2. (Apr., 1982), pp. 161-192.

LONG, Christopher P. "Aristotle's Phenomenology of Form: The Shape of Beings that Become”. Epoché, vol. 11, n. 2 (Spring 2007), pp. 435-448. 